MIPLC Studies

2

Murray Lee Eiland

Patenting Traditional Medicine 


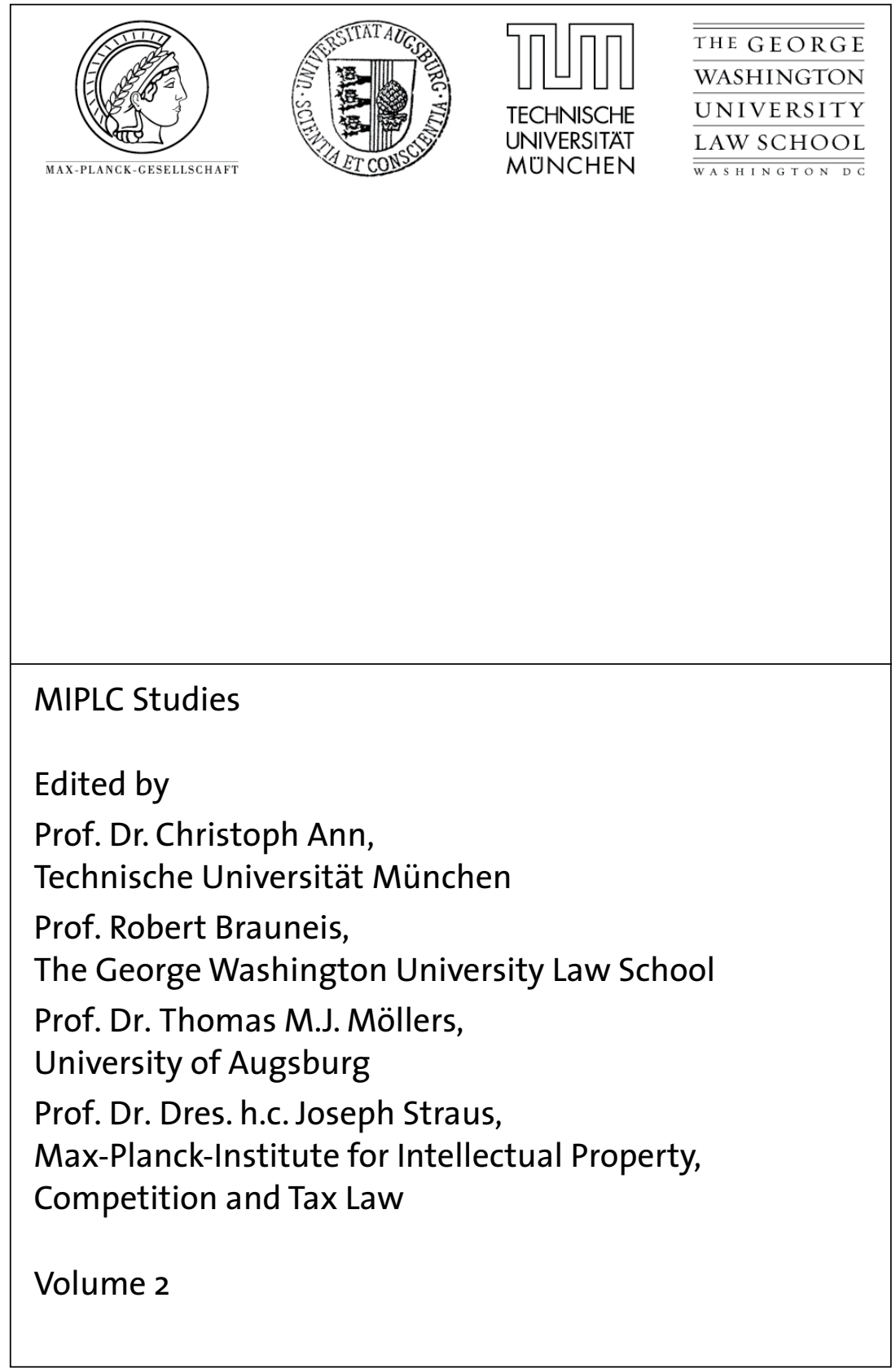


Murray Lee Eiland

\section{Patenting Traditional Medicine}


Die Deutsche Nationalbibliothek verzeichnet diese Publikation in der Deutschen Nationalbibliografie; detaillierte bibliografische Daten sind im Internet über http://www.d-nb.de abrufbar.

The Deutsche Nationalbibliothek lists this publication in the Deutsche Nationalbibliografie; detailed bibliographic data are available on the Internet at http://www.d-nb.de.

Zugl.: Munich, Munich Intellectual Property Law Center LL.M., Thesis., 2006

ISBN 978-3-8329-3766-9

\section{Auflage 2008}

() Nomos Verlagsgesellschaft, Baden-Baden 2008. Printed in Germany. Alle Rechte, auch die des Nachdrucks von Auszügen, der fotomechanischen Wiedergabe und der Übersetzung, vorbehalten. Gedruckt auf alterungsbeständigem Papier.

This work is subject to copyright. All rights are reserved, whether the whole or part of the material is concerned, specifically those of translation, reprinting, re-use of illustrations, broadcasting, reproduction by photocopying machine or similar means, and storage in data banks. Under $§ 54$ of the German Copyright Law where copies are made for other than private use a fee is payable to "Verwertungsgesellschaft Wort", Munich. 


\section{Inhaltsverzeichnis}

Patenting Traditional Medicine

Murray Lee Eiland*

INTRODUCTION

The Controversy

I. TERMINOLOGY OF TRADITIONAL KNOWLEDGE 10

1. WIPO Model Provisions 10

2. The Convention on Biological Diversity 11

3. Declaration of the Rights of Indigenous Peoples 12

4. Traditional Knowledge: A Certain Term? 13

5. IP Laws and Traditional Knowledge 13

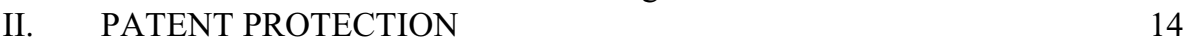

$\begin{array}{ll}\text { III. TRIPS } & 15\end{array}$

IV. US PATENT SYSTEM 16

1. Categories of Patent 16

2. Novelty 17

3. Joint Invention 20

4. Potential Conflict with TRIPS Obligations 21

V. INDIA 22

1. Patents 22

2. Tumeric 23

3. Indian Bio-Diversity Act 23

4. Neem 24

5. The Neem Patent at the EPO 25

6. Geographic Disparity in US Patent Law 25

7. Neem Patent in New Zealand 26

8. Databases 27

9. Fair Use 29

10. Is the Database Project Viable? 30

VI. DISCLOSURE OF ORIGIN 30

VII. PROSPECTING AGREEMENTS

VIII. GEOGRAPHICAL INDICATIONS 35

IX. TRADEMARKS 36

X. TRADE SECRET PROTECTION 37

XI. CHINA 39

1. Statutory Protection 39

2. Patent Law 40 
3. A Database of Traditional Chinese Medicine?

XIII. CONCLUSION 


\title{
Patenting Traditional Medicine
}

\author{
Murray Lee Eiland*
}

\section{INTRODUCTION}

Traditional medicines (TM) ${ }^{1}$ can form the basis of modern pharmaceuticals. Depending upon national laws, it is possible to protect TM with patents. For instance, a US patent can be issued that derived information or even genetic resources from the TM of another country. This has raised criticism from a number of different perspectives. Most notably there is a perceived conflict between traditional knowledge (TK) structures and patent law. Some question if TM is even an intellectual property (IP) right. There are a number of proposals to protect TM using other forms of IP rights, such as geographical indications and trade secret law. These issues are far from settled, and can have strong political overtones. Before going further, however, TM will be considered in the light of other IP rights.

TM has been a source for pharmaceuticals for a long time. Aspirin is a good example. The ancient Egyptians used willow leaves as an analgesic and anti-inflammatory drug. The Classical world was also familiar with the healing properties of this plant. Hippocrates $(460-370 \mathrm{BC})$ recommended the use of extracted juice from the bark of the white willow to suppress pain and fever. It was only in 1828 that the extract of willow bark was purified. In 1859 the chemical structure was identified. The drug was mass produced shortly thereafter. Bayer registered the compound on 1 February 1899 under the name of Aspirin. The 'a' stood for acetyl, and the 'spir' for Spiraea ulmaria, the plant from which the drug had first been isolated. Today it is the most popular analgesic in the world, and new discoveries are ongoing. ${ }^{2}$ In the case of aspirin, the TK that helped researchers to find the active ingredient was thought at the time to be in the public domain. If aspirin were patented in recent decades, there would no doubt be litigation over who supplied the TK. Other examples of drugs derived from natural

* BA Near Eastern Archaeology, UC Berkeley 1990; Dphil Oriental Archaeology, Oxford University 1995; MS Earth Sciences, UC Santa Cruz 2000; CPE Keele University 2004; BVC City University 2005; LLM Munich Intellectual Property Law Center 2006. This paper is an adaptation of a thesis submitted to the MIPLC as part of the LLM course. Special thanks are due to Dr. Tanuja Garde for comment and criticism, although any errors remain the responsibility of the author. The work was previously published in the Journal of the Patent and Trademark Office Society 89:1, 45-83. Permission has kindly been granted to reprint it in this volume.

1 According to the World Health Organization, the term traditional medicine refers to: "health practices, approaches, knowledge and beliefs incorporating plant, animal and mineral based medicines, spiritual therapies, manual techniques and exercises, applied singularly or in combination to treat, diagnose and prevent illness or maintain well being." World Health Organization Fact Sheet No. 134 http:// www.who.int/mediacentre/factsheets/fs134/en/print.html (last visited Sept. 5, 2006).

2 See generally DiAmOND JEFFrEYs, AsPIRIN: THE REMARKABLE STORY OF A WONDER DRUG (2004), for a general discussion of the history of aspirin. 
substances and that have been incorporated into mainstream medicine are morphine (1806), quinine (1823), atropine (1833) and digitalis. ${ }^{3}$

In 1982, it was estimated that about $50 \%$ of all filled prescriptions in the US originated from drugs that were derived - one way or another - from natural substances. This generated US sales of about 20 billion. ${ }^{4}$ Another estimate found that $3 / 4$ of the plants used in prescription drugs originally came to the attention of drug companies because of their use in TM. ${ }^{5}$ In 1995, the worldwide market value of TM derived pharmaceuticals was estimated to be $\$ 43$ billon. ${ }^{6}$ While one could argue about the precise values, TM has significant pharmaceutical applications. Drug companies are interested in acquiring TM, both natural substances, as well as the knowledge about how to use them. In the past, such knowledge was regarded as free information. The assumption was that no one had a right to this information, especially because there usually needed to be a long process of development to make TM into a patentable drug. Modern conceptions of the issue leave little doubt that TM can be an IP right. Considering the large profits generated by modern drugs, there has been increasing pressure to protect TM with patents. Several well-known cases of western companies patenting drugs based on TM has also raised concerns. Some advocates who don't support the patent system but who do wish income to 'trickle down' to the communities who developed the TM suggest that an entirely new legal framework be established. Patents are appreciated by this group as unsuitable:

First, the invention is not dated, so that it is not possible to determine the critical date. As it would have been used for a long period of time, it would lack novelty. Also, the inventor is not determined, since it is knowledge that belongs to the who community. Patents are granted to individuals, or a small group of them, not to an undetermined group of people. ${ }^{7}$

The main question that emerges is feasibility. Are patents suitable for protecting TM and, if not, what are the alternatives?

\section{The Controversy}

Bio-piracy is a term minted in the last decades to describe taking biological materials - including TM - and patenting them in the west. ${ }^{8}$ When this happens TK right holders allege a property right has been violated. The source of the information, as well as

3 See Barrie G. James, The Future of the Multinational Pharmaceutical Industry to 1990 61 (1977).

4 See Norman Myers, A WeAlth OF Wild SPECIES 90 (1983) citing an unpublished study by Norman Farnsworth in 1982.

5 See Jack Kloppenburg Jr., No Hunting! Biodiversity, Indigenous Rights, and Scientific Poaching, 15 CULTURAL SURVIVAL Q. 14 n. 3 (1991).

6 See Someshwar Singh, Traditional Knowledge Under Commercial Blanket, THIRD WorLd NeTWORK, http://twnside.org.sg/title/blanket-cn.htm (last visited Sept. 5, 2006). The Third World Network is an independent non-profit network of organizations. The calculation of this sales figure is difficult and of course subject to error.

7 Eliana Torelly de Carvalho, Protection of Traditional Biodiversity-Related Knowledge: Analysis of Proposals for Adoption of a Sui Generis System, 11 Mo. ENVTL. L. \& POL'Y REV. 53 (2004).

8 Paul J. Heald, The Rhetoric of Biopiracy, 11 Carduzo J. Int'l \& Comp. L. 519 (2003). 
the material itself, is not acknowledged. No compensation is paid. When a patent is issued, it is not held by the inventor. The patent will prevent the holder of the TK from taking out a patent themselves. Despite the accusations, however, a patent is granted for an invention that may have little in common with TM as practiced by an indigenous community. Bio-piracy is a very political issue.

This highlights the so called north-south divide. ${ }^{9}$ The accusation is that wealthy nations in the north rely upon colonial era conceptions of property in order to gain access to TK, including TM, for free. TK is not usually protected using a system of written laws in southern countries. It may be controlled as collective property by trained practitioners (such as a Shaman). ${ }^{10}$ The fact that the legal systems may be different - they may be termed traditional legal systems - does not make them less valid. It does, however, make compliance difficult. This quickly leads into the issue of disclosing the origin of biological materials as a pre-requisite for patent protection. Indeed, without knowing the origin there can be no thought of benefit sharing. ${ }^{11}$ Yet from a 'northern perspective' these proposals could hamper research and lead to higher drug costs. On the other side, some have suggested that protection of medical knowledge, including drugs, with patents is fundamentally incorrect. ${ }^{12}$ While this subject captures media and public attention, the patent system is unlikely to be replaced any time soon. ${ }^{13}$ The real questions are how patents can be used to protect TM, and how patents based on the misappropriation of TM can be stopped. Some consideration will also be paid to other legal methods of protecting TM that have been proposed as alternatives to patents.

TM involves both the substance itself (assumed here to be botanical) as well as the practices used to prepare it for use. Both India and China ${ }^{14}$ have ancient medical traditions, but they use very different methods of protecting it. The TM of these two countries will be used as a lens to explore some of the issues involved in patenting. There are then two important divisions in the analysis. The first is the kind of protection provided in national legislation. The second issue is the kind of protection offered to TM of other countries in the west as well as in international agreements. America will receive special attention. Prior use or (unpublished) knowledge of an invention in

9 See generally Gavin Stenton, Biopiracy Within the Pharmaceutical Industry: A Stark Illustration of How Abusive, Manipulative and Perverse the Patenting Process can be Towards Countries of the South. E.I.P.R. 26(1), 17-26 (2004).

10 See generally Craig D. Jacoby and Charles Weiss, Recognizing Property Rights in Traditional Biocultural Contribution, 16 STAN. ENVTL. L.J. 74, 90-91 (1997).

11 See Dr. Gerard Bodeker, Traditional Medical Knowledge, Intellectual Property Rights \& Benefit Sharing, 11 CARDOZO J. INT'L \& COMP. L. 785 (2003).

12 Examples of opposition include Indira Ghandi's statement that "... [t]he idea of a better-ordered world is one in which medical discoveries will be free of patents . ..". See Robert Gutowski, The Marriage of Intellectual Property and International Trade in TRIPS Agreement: Strange Bedfellows or a Match Made in Heaven? BUFF. L. REV. 713, 744 (1999) (reproducing a speech given in 1982 to the World Health Assembly).

13 For a discussion of the alternatives to patent protection, with particular reference to monopoly contracts, see Lester I. Yano, Protection of the Ethnobiological Knowledge of Indigenous Peoples, 41 U.C.L.A. L. REV. 486 (1993). The author notes that other alternatives would take a prohibitive amount of time to develop.

14 In China, TM comprises between 30 and $50 \%$ of the total consumption of medicine. See WHO Fact Sheet, supra note 1 . 
a foreign country is no bar to obtaining a patent in America. ${ }^{15}$ This is clearly in order to encourage US business and industry, but according to critics, it has devastating effects on the TK of other nations. ${ }^{16}$

Patents are a well established feature of the pharmaceutical industry. They can be used to protect TM, though they are not ideal. ${ }^{17}$ While many TM traditions are based on imprecise mixtures, scientific techniques can be used to isolate active ingredients that can in turn be modified subsequently. The end product, which may be wholly or partially synthetic, would be subject to patent protection. How this derived use of TM should be compensated is an open question. Before going further with the subject, however, it would be best to define terminology, starting with traditional knowledge (TK).

\section{TERMINOLOGY OF TRADITIONAL KNOWLEDGE}

TM is a branch of TK, and both lay at the intersection between biology and culture. The increasing use of biotechnology and the exploitation of genetic resources has engendered a polarized debate about how to acknowledge and compensate the holders of TK. In some cases, TK may be considered intangible, such as a dance sequence. ${ }^{18}$ $\mathrm{TM}$ as it is considered here is in another category. It is tangible and involves the knowledge and the exploitation of natural resources. For example, the information that a certain plant, prepared a certain way, is used to treat a particular disease is specific. Aspects of traditional medicine are therefore subject to patent protection, depending upon national legislation.

\section{WIPO Model Provisions}

The World Intellectual Property Organization (WIPO), is a specialized branch of the United Nations. WIPO, in cooperation with the United Nations Educational, Scientific and Cultural Organization (UNESCO), began work on defining TK in 1978. This led to the adoption in 1982 of Model Provisions. ${ }^{19}$ These model provisions were designed to be a template for national and further international legislation. They treat cultural property not as part of the international IP system, but rather define a new sui generis system. Article 1 of the Model Provisions states that folklore is a: "living, functional tradition, rather than a mere souvenir of the past." By inserting the word

1535 U.S.C. $\$ 102$.

16 A good example from Ecuador is the US patent on Ayahuasca that was later revoked. See Leanne M. Fecteau, The Ayahuasca Patent Revocation: Raising Questions about Current U.S. Patent Policy, 21 B.C. THIRD WORLD L.J. 69-70 (2001).

17 See Liz Hanellin, Protecting Plant-Derived Drugs: Patents and Beyond 10 CARduZo ARTS \& ENT L.J. 169 (1991).

18 It is very difficult to protect intangible TK. See Daniel J. Gervais, Spiritual but not Intellectual? The Protection of Sacred Intangible Traditional Knowledge, 11 CARDOZO J. INT'L \& COMP L. 467 (2003).

19 WIPO-UNESCO Model Provisions for the National Laws on the Protection of Expressions of Folklore Against Illicit Exploitation and Other Prejudicial Actions, 1982, available at http:// www.wipo.int/tk/en/documents/pdf/1982-folklore-model-provisions.pdf (last visited Sept. 5, 2006). 
'functional' here one may understand that this covers folklore as broadly understood. The main method of protecting folklore is copyright (Articles 5-10) and neighboring rights (Articles 11-14). Section 2 of the Model Provisions defines protected expres-

sions of folklore as: “... characteristic elements of traditional artistic heritage ...” The term folklore clearly encompasses artistic expressions, but it is not precisely defined. The framers of the Model Provisions apparently did not assume patent protection was an option. Recent international agreements do not use the term folklore.

\section{The Convention on Biological Diversity}

The 1992 Earth Summit in Rio de Janeiro led to the agreement entitled the Convention on Biological Diversity (CBD). The primary goal of the convention is to conserve biological diversity, promote sustainable use of its components, and promote a fair and equitable sharing of benefits from the use of genetic resources. Previously assumptions were that biological diversity was the common heritage of humankind. The CBD established that sovereign nations have ownership of their TK and biological resources. The preamble of the CBD states:

Recognizing the close and traditional dependence of many indigenous and local communities embodying traditional lifestyles on biological resources, and the desirability of sharing equitably benefits arising from the use of traditional knowledge, innovations and practices relevant to the conservation of biological diversity and the sustainable use of its components. ${ }^{20}$

This statement can be divided into two parts. The first part deals with the dependence on certain lifestyles on biological resources. The second part of the statement deals explicitly with rights. Instead of using the broad term 'traditional knowledge' alone, the document qualifies it with the terms 'innovations and practices.' TM is not specifically mentioned in the 1982 model provisions, but there is little doubt that it is included in the CBD as a 'practice.' The CBD also draws a distinction between indigenous and local communities. However, TK from either source is considered equivalent. The use of the term 'traditional' however, carries with it a major assumption. It suggests that there has been a period of cultural transmission that remains faithful to the past. ${ }^{21}$ The CBD, in including local communities in the same formulation, effectively sidesteps the issue of faithfulness to the past.

Article 8 of the CBD, is titled 'In-situ Conservation.' Provision (j) states that each contracting party shall, as far as possible and as appropriate, subject to its national legislation, respect, preserve and maintain knowledge, innovations and practices of indigenous and local communities embodying traditional lifestyles relevant for the conservation and sustainable use of biological diversity and promote their wider application with the approval and involvement of the holders of such knowledge,

20 The Convention on Biological Diversity came into force on 29 December 1993. Text available at http://www.biodiv/org/doc/legal/cbd-un-en.pdf (last visited Sept. 5, 2006).

21 See Tony Simpson, The Protection of Cultural and Intellectual Property Rights of Indigenous Peoples INTERNATIONAL WORK GROUP FOR INDIGENOUS AFFAIRS 18-22 (1997). 
innovations and practices and encourage the equitable sharing of the benefits arising from the utilization of such knowledge, innovations and practices.

Provision $8(\mathrm{j})$ leaves questions of protection to national legislation. It frames the issue in terms of promoting the wider use of sustainable methods of utilizing biological diversity. ${ }^{22}$ This provision tries not to restrict exploitation of resources by either the sovereign national government or the international community.

As a whole the CBD has had a limited impact as a template for further legislation. Few countries have met the minimum standards of protection. A WIPO survey asked 47 countries, not including the EU, if they had any specific legislation that addressed TK. Brazil, Costa Rica, Guatemala and the Philippines replied that they had specific laws, the rest said they did not. The United States, which is not a signatory to the CBD, stated that they do not have laws that specifically protect TK. The US reply continued that: “... it is important to keep in mind that intellectual property, whether of an existing or sui generis nature, serves as an incentive for future creative endeavors; by definition, traditional knowledge needs no incentive for development." ${ }^{, 23}$ The statement leaves open the question of what TK definition the US follows. However, the contention that TK needs no incentive for development is controversial.

Elements of the CBD, including provision $8(\mathrm{j})$ has had a significant impact on the laws of some countries. The Indian Biological Diversity Act 2002 clearly follows the $\mathrm{CBD}$. The CBD has also served as a basis for academic debate. While the US is not a signatory, there is increasing international pressure to recognize benefit sharing as an objective.

\section{Declaration of the Rights of Indigenous Peoples}

The Draft United Nations declaration on the rights of indigenous peoples of $1994^{24}$ also covers TK. Article 12 states:

Indigenous peoples have the right to practice and revitalize their cultural traditions and customs. This includes the right to maintain, protect, and develop the past, present and future manifestations of their cultures, such as ... ceremonies and technologies ... as well as the right to the restitution of cultural, intellectual, religious and spiritual property taken without their free and informed consent or in violations of their laws, traditions, or customs.

This document does not note TK specifically, but clearly includes TM in 'traditions and customs.' It goes much further than $8(\mathrm{j})$ of the CBD in that rights to TK are not

22 Much discussion stemming from the CBD is political and defines these rights as distict from IP rights. See Rosemary J. Coombe, Protecting Traditional Environmental Knowledge and New Social Movements in the Americas: Intellectual Property, Human Right, or Claims to an Alternative form of Sustainable Development?, 17 FLA. J. INT'L L. 115 (2005).

23 WIPO Survey on Existing Forms of Intellectual Property Protection for Traditional Knowledge. Document WIPO/GRTKF/IC/2/5, http://www.wipo.int/tk/en/questionnaires/ic-2-5/replies.pdf (last visited Sept. 5, 2006).

24 Draft United Nations declaration on the rights of indigenous peoples. See http://www.unhchr.ch/huridocda/huridoca.nsf/(Symbol)/E.CN.4.SUB.2.RES.1994.45.En?OpenDocument (last visited Sept. 5, 2006). 
determined according to national legislation but to laws, traditions and customs as defined by the indigenous peoples. The document leaves open the issue of how to define 'indigenous.' While the CBD has had some impact on subsequent legal thinking, the provision in this declaration has had little impact. While there is a great degree of certainty in adhering to published national laws, following unwritten laws, traditions or customs might be difficult in practice. ${ }^{25}$

\section{Traditional Knowledge: A Certain Term?}

For legal certainty, it would be best if there were a general understanding - if not consensus - reached in regards to the meanings of key terms such as TK. In practice, however, a precise definition may not be required. As an example, in patent law, general terms such as 'invention' have no definition in international treaties and national laws. Nevertheless, there is a clear understanding of the nature of a 'patentable invention.' In a similar way, copyright treaties and laws do not define the exact nature of literary, artistic, and scientific works, but rather concentrate upon how these expressions may be protected. $^{26}$

As a general guide, three main considerations assess the nature of TK: (1) whether it involves a process or product (2) whether it can be expressed in a common or in an 'indigenous' language and, most importantly, (3) whether it has been and will remain part of TK that can then form the basis for new TK in the future. ${ }^{27}$ The same conditions apply to TM.

\section{IP Laws and Traditional Knowledge}

The essence of the current international system of IP laws focuses on preserving a balance between the economic interests of the author of the invention or idea and society's needs as a whole. The two sides are mutually exclusive. Extreme positions include the abolition of the patent system on the one hand, and an extension of protection on the other. ${ }^{28}$ The protection of TK cannot fit easily into the current international IP framework. In both patent and copyright there are ways to determine the owner, but it is not possible to apply this model to all forms of TK. In some cases, TK could be

25 According to some academics there is a need for the codification of tribal laws without the imposition of dominant, western legal concepts. See Angela R. Riley, Straight Stealing: Towards an Indigenous System of Cultural Property Protection, 80 WASH. L. REV. 87 (2005).

26 See Wend B. Wendland, Intellectual Property, Traditional Knowledge and Folklore: WIPO's Exploratory Program IIC 496 (2002). The method of making TK fit into existing IP systems has been criticized in that it creates an unrecognizable hybrid that can no longer be considered TK.

27 Yinliang Liu, IPR Protection for New Traditional Knowledge: With a Case Study in Traditional Chinese Medicine. 4 E.I.P.R. 194, 195 (2003).

28 See Shubha Ghosh, Traditional Knowledge, Patents, and the New Mecantalism (Part II), 85 J. PAT. \& TRADEMARK OFF. SOC'Y 885 (2003). The author here defines three main positions: 1. appropriation: TK should be used by those best positioned to expoit it; 2 . moral rights: endorses the rights of TK right holders to use TK as they see fit; and 3. public domain: which would prohibit the commodification of TK. 
known to more than one group or it might not be possible to exactly trace the originator group. ${ }^{29}$ WIPO has suggested several goals by which the TK community could benefit from their IP. The issue goes beyond monetary compensation, and includes the prevention of unauthorized exploitation and the protection of the moral rights of the innovators of the TK. ${ }^{30}$ It is hoped that such a system would also stimulate innovation and creativity, which is a common element to the WIPO system and traditional IP rights.

\section{PATENT PROTECTION}

Patent rights prevent others from selling, manufacturing, making, advertising or otherwise using an invention or idea over which an individual has a patent. ${ }^{31} \mathrm{~A}$ patent does not confer a right to use the invention. A patent may be defined as a national grant of exclusive rights for a limited time for a new, useful invention. These rights are in general territorial so that an inventor wishing protection in a number of countries must obtain more than one patent. ${ }^{32}$ Patents effectively convey rights that are comparable to real property rights. ${ }^{33}$ While a land registry contains information about the nature and extent of property rights, a patent makes it clear to the public what rights exist within its scope. A patent must make clear what the patent holder will regard as an infringement and what remains in the public domain. Like tangible property, a patent may be legally transferred to another. ${ }^{34}$ Attempts have been made to ensure that patent laws are applied with uniformity on an international level. ${ }^{35}$ Some suggest that in the area of patents there is greater uniformity than in other areas of the law. In part, this is due to the colonial legacy of European powers, who share many common concepts.

The current international patent system can be traced to $18^{\text {th }}$ century European philosophical movements. It was then that craft traditions, protected by collective guilds, grew increasingly appreciated as an individual creation. The lone genius, independent inventor, or creative rebel was extolled. ${ }^{36}$ Some authors have suggested that the system of western science characterizes natural materials under the care of indigenous peoples as 'wild' or 'primitive.' Until recently, little attention was paid to informal (or unpublished) systems of knowledge. Many regarded TK as the freely available com-

29 See generally Graham Dutfield, The Public and Private Domains: Intellectual Property Rights in Traditional Knowledge, EleCtRONIC JOURNAL OF InTELleCtUAL PROPERTY RIGHTS (Mar 1999), available at http://www.oiprc.ox.ac.uk?EJWP0399.html (last visited Sept. 5, 2006).

30 See WIPO Report on Fact-Finding Missions on Intellectual Property and Traditional Knowledge 70 (1998-1999), http://www.wipo.int/tk/en/tk/ffm/report/index.html (last visited Sept. 8, 2006).

31 See Richard T. Holzman, Infringement of the United States Patent Right: A GUide for EXECUTIVES AND ATTORNEYS 11 (1995).

32 Philip W. Grubb, Patents for Chemicals, Pharmaceuticals and Biotechnology: Fundamentals of Global Law, Practice and Strategy 3 (1999).

33 See J.W. HARRIS, PROPERTY AND JUSTICE 3 (1996).

34 See Bob Dematteis and Andy Gibbs, Essentials of Patents 21 (2003).

35 See Matthias Brandi-Dohrn, Stephan Gruber and Ian Muir, European Patent law: Law AND PROCEDURE UNDER THE EPC AND PCT, 11 (1999).

36 See Angela R. Riley, Recovering Collectivity: Group Rights to Intellectual Property in Indigenous Communities, 18 CARDOZO ARTS \& ENT. L.J. 179 (2000). 
mon heritage of humanity. Under current intellectual property law, patentability remains systematically biased against TK communities. ${ }^{37}$

TK may have stimulated research leading to a patent. However, the TM may have little claim on the patent itself if a patent is obtained regarding the structure of a compound or the process of isolation. Where the use of the drug is the same as or similar to that of the source plant in TM, the connection between the TK and the invention is clear. The degree of the essential contribution of the TM depends upon the facts of every case. International agreements play a large role in establishing a base line of protection. The main question is how these agreements impact national legislation regarding protecting $\mathrm{TM}$ with patents.

\section{TRIPS}

The Trade Related Intellectual Property Agreement (TRIPS) is the international agreement that states the minimum level of protection that Global Agreement on Tariffs and Trade (GATT) member states must provide. ${ }^{38}$ It allows developing nations to bring their legislation in line with the agreement over a period of time. The result, eventually, should be a nearly uniform standard in countries that could differ substantially in terms of economic development. Some have argued that this system drains wealth and resources from poor nations. ${ }^{39}$

Article 8(j) of the CBD leaves it to national legislation to determine how to protect TK and biological resources. Article 27(3) of TRIPS allows governments to exclude from patentability plants and animals other than micro-organisms. The enactment of TRIPS resulted in violent protests in India, polarized by the US patent of chemicals isolated from the neem tree. India has proposed that TRIPS be amended to comply with the CBD (although some other nations see no inherent conflict). The Indian proposal calls for: 1 . benefit sharing agreements, 2 . the disclosure of origin for genetic resources, 3 . patent applications open to public scrutiny, 4. the expansion of geographical indication protection and, 5. requiring companies that make environmentally sound technology to sell it at a fair price. ${ }^{40}$ Issues 1 to 4 will receive special attention here, as they are central to the debate of patenting TM. Because the main impetus for amending TRIPS came from alleged US infringement of Indian rights, the US patent system will be considered next.

37 See Naomi Roht-Arriaza, Of Seeds and Shamans: The Appropriation of the Scientific and Technical Knowledge of Indigenous and Local Communities, 17 MICH. J. INT'L L. 929-930 (1996).

38 General Agreement on Tariffs and Trade-Multilateral Trade Negotiations (the Uruguay Round): Agreement on Trade-Related Aspects of Intellectual Rights, 33 I.L.M. 81 (1994) [hereinafter TRIPs Agreement].

39 For an examination of India in particular, see Muria Kruger, Harmonising TRIPS and the CBD: $A$ Proposal from India 10 MIN. J. GLOBAL TRADE 169 (2001). India was a particularly vocal opponent of TRIPS at the Uruguay Round.

Id. at 179 . 


\section{Categories of Patent}

The Patent Act governs what can be protected via patents in the US. ${ }^{41}$ The invention must fall in one of three categories: 'manufacture,' 'process,' or a 'composition of matter. ${ }^{42}$ In practice, not all categories offer the same level of protection. For instance, a drug may not be protected by a utility patent because it is not possible to prove it is a 'manufacture' or 'composition of matter'. In this case, the process itself could be patented. This was the case with Reserpine, a drug used to treat hypertension, which was derived from the plant Rauvolfia sepentia. ${ }^{43}$ Process patents can protect the method used to produce (either manufacture or isolate) a drug. These patents are regarded as fairly weak in relation to a patent on the product itself. An alternative way to make a substance could be found that would not infringe. In contrast, even if a producer found a way to make a substance in a different way and protected by a 'composition of matter' patent, it would infringe. A patent on composition is effectively protection for a product. For example, if an inventor discovers that a particular ratio of non-patentable natural substances can be used to treat a particular disease, then a composition patent could be issued that gave the owner the right to use this combination.

So called use patents are sometimes referred to as weak patents in a business environment. For example, Company One could have invested a considerable amount of money and hold a use patent on a drug. Company Two could, using published data, obtain approval to use a drug for a single indication not covered by Company One's use patent. Company Two could then sell the drug for every indication at a low price. They would have expended much less money than Company One, and would effectively drive the price down. ${ }^{44} \mathrm{~A}$ use patent is in a particularly precarious position if the substance is natural or commonly available and has multiple uses. Some authors suggest that although the US has very strong patent protection for natural substances, particularly when compared with other industrialized nations, it is not strong enough to encourage investment in natural drugs. ${ }^{45}$

41

42

43

44 ture of large sums of money for a substance with a poor patent position to our stockholders? How would our management look if we spent millions of dollars to develop carnitine, only to have another company, using already published data, obtain FDA approval to use it for a single indication not covered by your use patent and sell it at a very low cost to everyone for every indication?"

45 See id. at 53. "Relatively few NDA's for natural substances are submitted to the FDA for review. There is little doubt that limited exclusivity is not a powerful incentive for undertaking research and development of natural substances." However, the author makes it clear that natural substances are problematic for a number of reasons, particularly the FDA policy towards herbal mixtures. See id.at 55. ". . . the FDA would more likely than not request that the specific active ingredient be isolated. Lacking sufficient patent protection and technology, few companies would go forward with this enormous effort. Many natural molecules are large and complex and cannot, even if chemically characterized, be produced in large quantity." Id.

35 U.S.C. $\S \S 101-104$ (1988).

at $\S 101$.

See StePhen L. DeFelice, From Oysters to Insulin: Nature and Medicine at Odds 28 (1986). 
Several categories of materials cannot be patented. The most obvious are substances that occur naturally. The US Patent and Trademark Office (USPTO) and courts have traditionally used the term 'work of nature' to exclude subject matter from patent protection. ${ }^{46}$ The Manual of Patent Examining Procedure states: “. . . a thing occurring in nature, which is substantially unaltered, is not a 'manufacture'." ${ }^{47}$ In practice, naturally occurring chemicals can be patented if their structures have not been published. Simply isolating a natural product, even if the isolate is purer than its natural equivalent, is unpatentable unless there is an unexpected effect. ${ }^{48}$ If a useful natural drug has been published, a drug company would be forced to find a novel derivative in order to secure a composition patent. ${ }^{49}$ The case General Electric Co. v. DeForest Radio Co. ${ }^{50}$ demonstrates that the courts are reticent to grant a patent for a substance that occurs in nature. In this case, DeForest converted tungsten, a very brittle metal, into what he termed to be an 'entirely new metal' that could be used for the filaments in light bulbs. ${ }^{51}$ The court conceded that the invention was a 'tremendous' technical advance but the fact that the metal existed in its pure form in nature was decisive. The court invalidated the product patent. ${ }^{52}$ Based on public policy, the court could not allow a patent to be granted for natural material that could prove essential for competing concerns. The ultimate goal of patents is to promote invention and not grant a monopoly per se. A process that allowed protection with a patent, yet this was a far weaker form of protection.

The term 'composition of matter' as in 35 U.S.C. $§ 101$ includes: “... all compositions of two or more substances" and "... all composite articles, whether they be the results of chemical union, or of mechanical mixture, or whether they be gases, fluids, powders or solids. ${ }^{, 53}$ The inventive step is easier to demonstrate when there is a mixture that is not found in nature.

\section{Novelty}

US patent law offers a monopoly period in exchange for a detailed disclosure, so that the public may replicate the invention. ${ }^{54}$ A successful patent, of whatever category, must also be useful ${ }^{55}$, novel ${ }^{56}$ and be non-obvious. Utility is a test to make sure the

Funk Bros. Seed Co. v. Kalho Inoculant Co., 333 U.S. 127 (1948). The case particularly addressed the terms "product of nature" and "product derived from nature." Id. at 134-35. These were held to be legal conclusions and not definitions. A product with a natural source could still be subject to patent protection.

M. Jacob, Patentability of Natural Products, 52 J. PAT. \& TRADEMARK OfF. SOC'Y 473 (1970) (citing the Manual of Patent Examining Procedure $\$ 706.03(\mathrm{a})$ ).

48 Ex parte Gray, 10 U.S.P.Q.2d (BNA) 1922, 1924 (Bd.of Pat.App. \& Int. 1989).

49 See Medicinal Plants: Pills in a Haystack, ECONOMIST, Feb 24, 1990, at 87.

$50 \quad 28$ F.2d 641, 642 (3d Cir. 1928).

$51 \quad I d$.

52 Id. at 643.

53 Shell Dev. Co. v. Watson, 149 F. Supp. 279, 280 (D.C., 1957).

54 The Uruguay Round Agreements Act, signed in 1994, changed the term of a US patent to 20 years from the earliest filing date. 35 U.S.C. § (c)(1).

5535 U.S.C. $\$ 101$.

56 Id. at $\S \S 101-102$. 
public can benefit, which is easy to satisfy in the case of most drugs. Novelty makes sure that the claimed inventor has patented something that is new. Increasingly, evidence of TM can be used to destroy novelty in some jurisdictions, but in the US the situation is much more difficult.

According to 35 U.S.C. $\S 102$ (a) a person shall be entitled to a patent unless: "the invention was known or used by others in this country, or patented or described in a printed publication $^{57}$ in this or foreign country, before the invention thereof by the applicant for a patent." If an invention were known or used ${ }^{58}$ in the USA, there is no need for it to be in a printed publication in order to bar a subsequent patent by another party. 'Knowledge' does not refer to what is known or understood in an abstract sense. ${ }^{59}$ Private or secret knowledge will not destroy novelty. ${ }^{60}$ Novelty can be destroyed by the invention existing in a printed publication in the USA or abroad. Knowledge or use abroad will not render a US invention invalid if it is not printed. The latter point relates particularly to foreign TK.

35 U.S.C. $\$ 102$ (b) states: "the invention was patented or described in a printed publication in this or a foreign country or in public use or on sale in this country, more than one year prior to the date of the application for patent in the United States ..." The critical word here is application. An application will be barred if all elements of the invention have appeared in a printed publication in the US or abroad more than one year prior to the application. Public use or sale in the US more than one year prior would also bar an application.

There have been proposals to reform $\S 102$ (b) so that the geographical limitation would remain in place in cases of undisclosed third party conduct, but would be removed if an inventor commercialized their invention outside of the US beyond the one year grace period. ${ }^{61}$ Both sections make clear that foreign prior art must be a printed publication to destroy novelty. The situation may have been clear in 1836 , when the first geographical limitation entered US patent law. Because of difficulties of access, an unprinted foreign invention was not accessible by the general public in the US. Now, with ease of transport, there is concern than the limitation facilitates encroaching on the public domain. More seriously, according to some, it may not be the best way to promote the dissemination and promotion of technology. ${ }^{62}$ The fact

57 A printed publication must be fixed in a tangible medium of expression and be disseminated as well as accessible. Typewritten and accessible patent applications in foreign countries are not printed publications. See Steven J. Rothschild \& Thomas P. White, Printed Publication: What is it Now?, $70 \mathrm{~J}$. PAT \& TRADEMARK OFF. SOC'Y 42 (1988).

58 A prior user must physically embody the invention and not conceal the use, in other words it must be accessible to the public. See 1 DONALD CHISUM, PATENTS: A TREATISE ON THE LAW OF PATENTABILITY, VALIDTY AND INFRINGEMENT § 3.05 [2][a] (1995).

59 United States v. Adams, 383 U.S. 39, 148 U.S.P.Q. (BNA) 479 (1966). The court in this case stated that an inoperable or failed invention would not anticipate. In the case Verdegaal Bros., Inc. v. Union Oil Co., 814 F.2d 628, 632, 2 U.S.P.Q.2d (BNA) 1051, 1053 (Fed Cir. 1987) it was decided that even if the inventor did not recognize a function or process, if it was inherent (considering someone skilled in the art), then it can anticipate.

6035 U.S.C. $\$ 102(\mathrm{~g})$ states that novelty will not be destroyed if: "before the applicant's invention thereof the invention was made in this country by another who had not abandoned, suppressed, or concealed it."

61 William LeMarca, Reevaluating the Geographical Limitation of 35 U.S.C. $\$ 102$ (b): Policies Considered, 22 U. DAYTON L. REV. 25, 50-52 (1996).

62 John Golden, Biotechnology, Technology Policy, and Patentability: Natural Products and Invention in the American System, 50 EMORY L.J. 101, 104-05 (2001). 
that most TK is unwritten presents a problem. A foreign company could apply for a US patent based on foreign TM that is only known from oral sources. In this case, they may be held to be bio-pirates, but they would be following the letter of US law. There could also be another example of bio-piracy. For instance, if TM has been printed by ethnographers, a one year time limit would begin at the date of publication. Even if a TM practice were ancient, and published without the permission of the community, there could be a bar to a patent application under 35 U.S.C. $\$ 102$ (b). ${ }^{63}$ Even academics with no thought of financial gain could be considered bio-pirates.

The above considerations aside, the US patent law offers another hurdle. TM developed over a period of time and faces problems in that it may be difficult for an individual to demonstrate that they were the first to invent. 35 U.S.C. §102 (f) states the originator must: “... himself invent ${ }^{64}$ the subject matter sought to be patented." Much TK - as well as TM - does not have a well defined author. Others in the community could make a claim to have contributed to the invention. ${ }^{65}$ Some authors have suggested that some drugs could face lack of novelty issues on the basis of TM:

For example, the Rosy Periwinkle originally was used in its "natural" form in Madagascar to treat diabetes. Its derivative drugs, vincristine and vinblastine, are used to treat Hodgkin's disease and childhood leukemia. These drugs were patented. Now, however, after many years, research is being conducted to develop a diabetes drug from the Rosy Periwinkle. This new drug, if it is ever developed and marketed, may not be patentable because the use of this particular plant to treat this particular disease is neither novel nor non-obvious. ${ }^{66}$

As with so many other examples of the patentability of TM, this would depend on the exact facts of the case. The question would revolve around the connection between the substance as described in the TK and the drug. If there was a significant difference between the two (for example if the drug did not exist in a pure form in nature) ${ }^{67}$ a patent could be granted even if it was clear that Rosy Periwinkle was used to treat diabetes.

Issues of novelty (as well as obviousness) relate to the technology used in the invention. An imitative pharmaceutical company, perhaps based in a developing country, may infringe outright. This may be a matter of policy in order to make drugs available for a low price. Research based companies in developed nations with strong patent protection can synthesize non-infringing alternatives. ${ }^{68}$ It therefore appears that, in this instance, there is a bias against patenting TM as used in small to medium sized

63 See Gelvina Rodriguez Stevenson, Trade Secrets: The Secret to Protecting Indigenous Ethnological (Medicinal) Knowledge, 32 N.Y.U. INT’L. L. \& POL. 1119, 1137 (2000).

64 US patent laws only reward the inventor. If it is possible to prove that an invention was discovered in a foreign country and simply imported into America the patent would be invalid. Cuno Eng'g Cort. v. Automatic Devices Corp., 314 U.S. 84, 91 (1941).

65 See Mark Hanning, An Examination of the Possibility to Secure Intellectual Property Rights for Plant Genetic Resources Developed by Indigenous Peoples of the NAFTA States: Domestic Legislation under the International Convention for Protection of New Plant Varieties, 13 ARIZ. J. INT'L \& COMP. L. 175, 196 (1996).

66 See Hanellin, supra note 17, at 179.

67 The case Merk \& Co v. Olin Mathieson Chem. Corp., 253 F. 2d 156 (4th Cir. 1958) held that vitamin B12 was patentable in crystalline form even though it was derived from an unpatentable natural substance. It did not exist in crystalline form in nature, so it differed in kind from the impure natural state. 
enterprises, particularly in developing countries. It is clear the US patent law was formulated long before the debate on patenting TM existed, but this is cited as one more example of the divide between north and south. In other instances, it appears that US law offers options that are under-exploited by those wishing to protect TM. A good example is the provisions for patenting a joint invention.

\section{Joint Invention}

A common refrain is that patent law does not allow TK holder contributions to be recognized. Both statue and case law in the US contradicts this view. 35 U.S.C. $§ 116$ states that an invention can be made by two or more persons even if they did not work physically together (or at the same time) and did not make the same type of contribution, and did not make a contribution to every claim. The case law ${ }^{69}$ suggests that even if drugs were developed from plants identified in literature surveys, this would be enough to qualify as a joint invention. Some element of reliance appears to be enough, although there is no definitive judicial statement on the minimum standard needed for collaboration. $^{70}$

If the invention simply provided knowledge that was already in the public domain the provider would not qualify as an inventor. There is a need to demonstrate some degree of conceptual connection between the information and invention. Some authors suggest that in recognizing TK, there is a risk:

Legislatures and courts have developed carefully calibrated regimes that effectively balance the competing interests of the inventor in obtaining a patent monopoly and of the general public in preventing the grant of an undeserved monopoly right that diminishes the public domain. Amending patent law to provide rights to traditional knowledge would disturb this balance, risking wide-range disruption of the entire system that would require even more legislative work than creating a narrow, new regime. ${ }^{71}$

The worst case scenario is far from proven. It is difficult to appreciate how applying for a patent held between joint inventors would cause large scale disruption. The examination process remains the same. The passage above seems to suggest that TK is part of the public domain, and in recognizing it as a contribution to the final invention, it would somehow alter the patent granting process. Recognizing a TK holder as a joint inventor does not conflict with international obligations. In the future it is possible that some provision regarding registering a patent as a joint invention could be part of prospection agreements.

68 Curtis M. Horton, Protecting Biodiversity and Cultural Diversity Under Intellectual Property Law: Toward a New International System, 10 J. ENVTL. L. \& LITIG. 17 (1995).

69 See Michael J. Huft, Indigenous Peoples and Drug Discovery Research: A Question of Intellectual Property Rights, 89 Nw. U.L. REv. 1712-1722 (1995).

70 See id.

71 Jacoby and Weiss, supra note 10 at. 99. 


\section{Potential Conflict with TRIPS Obligations}

According to critics, a prior art search in the US involves two different standards. According to 35 U.S.C. §102, evidence of foreign public knowledge or use of an invention under consideration for a patent is excluded. This is represents a geographic disparity. ${ }^{72}$ A central tenant of both the Paris convention and TRIPS is the national treatment principle, whereby: “. . . each Member shall accord to the nationals of other Members treatment no less favorable than that which it accords to its nationals with regard to the protection of intellectual property" as is outlined in Article 3:1 of TRIPS. The large number of foreign patents registered in the US demonstrates that in some regards the USPTO does not discriminate against non-US interests. However, the geographical limitation has been cited as a discriminatory provision. ${ }^{73}$ A group based outside of America could have an unprinted and unpublished aspect of their TK appropriated by a US patent.

In contrast, if the same TK was known to an indigenous group living in the US, a patent would be barred on the grounds that it was known as used by others in the US. ${ }^{74}$ According to TRIPS, this issue is for the national legislature to decide. According to 35 U.S.C. §104 evidence of unpublished foreign knowledge can be used to challenge priority. The purpose of introducing this evidence would be to support a foreigner's claim that they introduced the invention into the US before another. ${ }^{75}$ Section 104 allows foreigners to obtain US patents on the basis of foreign activity. This is essentially 'national treatment.' In contrast, a change to section 102 to recognize foreign anticipation would prevent US inventors from obtaining patents. ${ }^{76}$ There seems to be little ground for claiming that the US is in violation of TRIPS, other than some claim that this provision harms TK right holders.

Rule 37 C.F.R. $§ 1.105$, titled Requirements for Information, gives USPTO patent examiners the right to require an applicant to provide information that is reasonably necessary to examine the application. C.F.R. $§ 1.56$ imposes the duty of disclosure and candor on everyone associated with an application. If a party attacking a patent is able to show that information regarding patentability was intentionally withheld, the patent could be rendered unenforceable due to inequitable conduct. This should encourage applicants to disclose even unpublished information, particularly if requested by an examiner. ${ }^{77}$ It is clear that US patent law is flexible enough to accommodate TM (as is the case for joint inventions) but it is up to the right holders to use the law. Two recent cases pitted India against the USPTO in an effort to uphold the rights of TK right holders.

72 See Margo A. Bagley, Patently Unconstitutional: The Geographical Limitation on Prior Art in a Small World, 87 MinN. L. REV. 679 (2002).

73 Fecteau, supra note 16.

74 See de Carvalho, supra note 7, at 54.

75 Breuer v. De Marinis, 558 F. 2d 22, 194 U.S.P.Q. (BNA) 308 (C.C.P.A. 1977).

76 Shayana Kadidal, Subject-Matter Imperialsim? Biodiversity, Foreign Prior Art and the Neem Patent Controversy, 37 IDEA 401 (1997).

77 See Bagley, supra note 72 , at 740 . 


\section{Patents}

The Indian Patents and Designs Act of 1911 was modeled after English law. ${ }^{78}$ The high cost of pharmaceutical products led to changes in the 1970 Indian Patent Law. Chapter II of the 1970 Indian law (inventions not patentable) would make it very difficult for most TM to be protected. ${ }^{79}$ Section 3(e) states: "a substance obtained by a mere admixture resulting only in the aggregation of the properties of the components thereof or a process for producing such substance." This provision would apparently require the applicant to demonstrate that the mixture yielded unexpected results. Section 5 of the 1970 Indian law is detrimental to drugs in general and to TM in particular. For inventions: "intended for use, or capable of being used, as food or as medicine or drug, ${ }^{, 80}$ no patent can be granted for the substance itself, but claims for the method or process of manufacture would be allowed. ${ }^{81}$ By dispensing with product patents, the law gave particular incentives to finding efficient methods of manufacture. It also left generic drug manufacturers with many possibilities. At the same time, it aggravated western pharmaceutical companies. As an unintended consequence for TM, new methods of manufacture may be difficult to formulate. This would effectively require melding TM with science. While China has invested substantial sums to integrate scientific methods with TM, India has not.

India received the deadline of January 1, 1995 to comply with WTO requirements as established in TRIPS Article $65.4{ }^{82}$ This article allows for product patent protection to a particular area of technology to be delayed for an additional five year period. The Patents (Amendment) Act $2005^{83}$ introduces product patents for medicines for the first time in 35 years. The Amendment omits section 5 of the 1970 Act. $^{84}$ This removes the stricture against patenting medicines. In the case of TM, section 3 (d) still

78 Indian law has been criticised for following western models: "Implying that the solution is based on the same intellectual property concepts of the West, which many developing countries have accused of producing an intolerable injustice. I have tried to highlight how flippant consideration of the inherent epistemological diversity between the North and South has skewed the biodiversity debate, and masked the unacceptability of a patent right or claim as an answer to biopiracy." Remigius N. Nwabueze, Ethnopharmacology, Patents and the Politics of Plants' Genetic Resources, 11 CARDOZO J. INT'L \& COMP. L. 585 (2003).

79 Patents Act of 1979 http://indialaowinfo.com/bareacts/pat.html\# Toc 4994653) (last visited Sept. 5, 2006). For a general discussion of the Indian Patents Act and medicine, see PHILIP W. GRUBB, PATENTS FOR CHEMISTS 251 (1982). Chapter I 2 (1) notes that medicine or drug includes: "(I) all medicines for internal or external use of human beings or animals, (ii) all substances intended to be used for or in the diagnosis, treatment, mitigation or prevention of diseases in human beings or animals." While not noted specifically, TM could be included in this list as well, although other aspects of the Act would make it difficult for TM to be included under patent protection.

80 Indian Patent Act of 1979 5(1)(a).

81 See id. at 5(1)(b).

82 Compliance with TRIPS will lead to many changes. See Fact Sheet: Changes to India's Patents Act and Access to Affordable Generic Medicines after Janurary 1 2005. http://healthgap.org/press releases/04/121404_HGAP_FS_INDIA_patent.pdf\#search=022India $\% 20$ patents $\% 20$ act $\% 22$ (last visited 1 Sept 1996).

83 The Patents (Amendment) Act 2005. English text at http://patentoffice.nic.in/ipr/patent/patent_2005. pdf\#search=\%22India\%20patents\%20act22 (last visited 1 Sept 1996).

84 Id. at $\S 4$. 
applies. TM will continue to be difficult to patent in India. The Amendment lists what are not inventions:

the mere discovery of a new form of a known substance which does not result in the enhancement of the known efficacy of that substance or the mere discovery of any new property or new use for a known substance or the mere use of a known process, machine or apparatus unless such known process results in a new product or employs at least one new reactant. $^{85}$

The principal Act of 1970 has a similar provision, but it does not specifically consider an invention to be a new use of a known substance that results in enhancement of the 'known efficacy.' While case law will have to be developed, this appears to be favorable to patenting some TM. However, given that the US has a huge pharmaceutical market, there have been instances where Indian TM has been patented in America.

\section{Tumeric}

In 1995, the US patent office granted a patent $(5,401,504)$ for tumeric (Curcurma longa) for the 'invention' of wound healing. The applicants were a team of two scientists (expatriate Indians) from the University of Mississippi. The plant was well known in India for both culinary use and as a traditional medicine. Greeks and Romans also knew it for its medical properties. The Council of Scientific and Industrial Research in India challenged the patent. It was invalidated ${ }^{86}$ for lack of novelty by the USPTO, who cited prior art in Indian TK. This is the earliest example of a successful challenge to a patent based on TK. ${ }^{87}$

\section{Indian Bio-Diversity Act}

As a result of several cases dealing with the purported infringement of TK, the First Inter-Ministerial Committee on Protection of Rights of Holders of Indigenous Knowledge was convened in New Delhi. ${ }^{88}$ The Committee focused primarily on protection and explored possibilities for future legislation. This meeting gave impetus to the Biological Diversity Act 2002, ${ }^{89}$ which specifically addresses TK. Broadly, it seeks to regularize access to genetic materials on the one hand, while protecting TK on the other. It provides for more centralized decision-making. Chapter 3 of the Act gives exclusive rights to the Central government in the form of the National Biodiversity

85 Id. at $\S 3$.

86 See Reexamination Certificate B1 (3500th) (Apr. 21, 1998) (cancelling claims in U.S. Patent No. $5,401,504)$.

87 See Graham Dutfield, Trade Related Aspects of Traditional Knowledge, 33 CASE W. RES. J. INT'L. L. 239 (2001).

88 See Srividhya Ragavan, Protection of Traditional Knowledge, 2 MinN. InTELl. Prop. Rev. 1, n. 272 (2001), for a discussion of the minutes.

89 Biological Diversity Act 2002. English text of Act is available on http://grain.org/brl_files/indiabiodiversityact-2002.pdf (last visited Sept 1, 2006). 
Authority (NBA) to be located in Chennai, although regional offices can be established with permission of the Central Government. Thus, local offices can address community needs.

Chapter 2 (6:1) of the Bio-diversity Act establishes that no person shall apply for an IP right by whatever name in or outside of India for any invention: "based on any research or information on a biological resource obtained in India" without prior approval of the NBA. If a person applies for a patent, permission of the NBA may be obtained after the patent's acceptance but before the sealing of the patent by the patent authority. The Act clearly covers TK with the inclusion of the phrase 'information on a biological resource.'

Chapter 2 (6:1:2) of the Bio-diversity Act establishes that while approval may be granted, the NBA may: “...impose benefit sharing fee or royalty or both or impose conditions including the sharing of financial benefits." This provision clearly follows the benefit sharing provisions of $8(\mathrm{j})$ of the CBD.

The new act has also drawn criticism in that even an Indian citizen or company registered in India will have to obtain permission in order to utilize ${ }^{90}$ biological resources according to Chapter II (7). Chapter II (7) states this will not apply to local communities as well as those practicing TM. Nevertheless, the fear is that this may in fact prevent basic research by non-local groups (such as universities) in India. The controlling body apparently holds that while domestic companies will have to register with authorities, no up front payment will be involved. Benefit sharing will be negotiated on a case by case basis. ${ }^{\text {. }}$

Chapter 5 (4) of the Bio-diversity Act states that the NBA shall give public notice of every approval for use of biological resources. This public scrutiny serves as a safety valve to allow other right holders to come forward. This is in keeping with India's proposal to revise the TRIPS agreement. ${ }^{92}$ The Bio-diversity Act clearly signals India's intention of asserting rights to both biological resources and TK. It specifically addresses the problem of foreign companies patenting Indian TM.

The overall effect of the Act remains to be determined. If the law is too restrictive it could hamper research with burdensome administrative procedures. At best, however, it could protect national sovereignty in biological resources, including TK. While it is designed to protect the needs of local communities, the structure of the NBA suggests it will be more of a government organ. This being said, in an increasingly international environment it may require considerable resources to challenge the validity of US patents, as the neem controversy demonstrates.

\section{Neem}

The neem tree is a source of TM used in India. Although the issue is not specifically related to patenting TM, it highlighted many of the concerns countries have about pro-

90 The exact words are: “. . . commercial utlization or bio-survey and bio-utilisation.”

91 See P.T. Jyothi Datta Bio-diversity Bill: Choking bio-piracy or research? THE HINDU (2002), http:// www.blonnet.com/bline/2002/12/15/stories/2002121501710300.htm (last visited Sept. 5, 2006).

92 See Kruger, supra note 40. 
tecting their TM. Indian texts dating back two millennia state that neem could be used as an insect repellant, medicine, and cosmetic. W.R. Grace \& Co. - Conn. filed patent applications (the US, European and New Zealand applications are considered here) covering a hydrophobic extract of the neem tree, an oil, for use as an insecticide and fungicide. ${ }^{93}$ The chemical called Azadirachtin was identified as the active substance. A process to stabilize this chemical in water was patented, as was the stabilized form of the chemical. ${ }^{94}$ The company did not apply for an Indian patent because the law at the time did not grant patents for agricultural products. ${ }^{95}$ The foreign patents therefore drew a rapid response from India.

\section{The Neem Patent at the EPO}

The European Patent Office (EPO) ${ }^{96}$ did not uphold the granting of the patent; it rejected it for lack of inventive step. Article 52(1) of the Munich Convention states that patents are granted on the basis of novelty, inventive step, and suitability of industrial application. Novelty is determined in relation to the state of the art, which according to Article 54(2) of the Munich convention means: “... everything made available to the public by means of a written or oral description, by use, or in any other way, before the date of filing of the European patent application." Unlike the case for the US system, where there is a clear division between information originating inside and outside the state, there is no such distinction here. The EPO can consider prior art that could be embodied orally or in practice, and not simply according to printed sources. These provisions clearly protect TK, the bulk of which is not written. In the neem case, however, the EPO did not consider TK rights per se.

\section{Geographic Disparity in US Patent Law}

The patent on the chemicals derived from neem was upheld in the US. Indian TK did not serve as prior art. While some authors have suggested that it is unconstitutional for the US to retain geographic disparity in its patent laws (35 U.S.C. $\$ 102),{ }^{97}$ other authors note that by not allowing foreign material to serve as prior art, there is an incentive to commercialize products in the USA. This could lead to compensation for the keepers of TK through contract law. ${ }^{98}$ Under this view, the US does not allow patents to encompass what is in the public domain, but instead encourages the develop-

See generally Emily Marden, The Neem Tree Patent: International Conflict over the Commodification of Life, 22 B.C. INT'L \& COMP. L. REV. 279 (1999).

94 See U.S. Patent No. 5,281,618 (issued Jan 25, 1994).

95 See Indian Patent Act 1970 3(h) stating that a "method of agriculture or horticulture" is not an invention and therefore cannot be patented.

96 The European Patent Organization was put into place by the Munich Convention of 1973. As of March 2003 there were 28 member states. The system centralized the application process, while a valid patent is issued in as many states as requested in the application.

97 See Bagley, supra note 72.

98 See Craig Allen Nard, In Defense of Geographic Disparity 8 IIC 909 (2003). 
ment of products that may otherwise remain undeveloped. In the case of neem, this would lead to the products derived from the plant being available to European customers only in the US but at 'monopolistic' pricing levels. Those in favor of geographic disparity would suggest:

It is reasonable to assume that, absent a geographic distinction (i.e. absent patent rights), a pharmaceutical firm would not invest millions of dollars in commercialization efforts, thus depriving all consumers. Moreover, exploiting the patent in the rich United States market could lead to significant profits that would form part of a benefit sharing arrangement. ${ }^{99}$

The fear is that Grace's patent in the US will deny Indian access to the US market. This may in turn allow Grace to control the cash-crop market of neem in India, as well as potentially bidding the price of neem seed beyond the reach of competitors. ${ }^{100}$

There are arguments both for and against the retention of geographical disparity in US patent law. However, it is clear that the framers of the law were concerned with the development of innovation in the US. In 1836 they did not envisage that the disparity could allow a US company to effectively control the world wide market in a product, such as could be said for neem. While such a monopoly could effectively develop a product, there is a great risk that such a position in the market could be abused.

\section{Neem Patent in New Zealand}

The New Zealand Patent Office had also issued an equivalent patent to the EPO. The main difference is that the standard of novelty is determined according to prior publication in New Zealand. Unless the TK has been published in that country, there can be no countering the claim for lack of novelty. The neem patent in New Zealand was not revoked. This has raised a number of problems in New Zealand where a large indigenous community with extensive oral traditions exists.

In 2000, the government of New Zealand began a review of the Patents Act of 1953. In March 2002, the document Boundaries to Patentability ${ }^{101}$ was released. Information from submissions was incorporated into the Patents Act Review on 28 July 2003. On 20 December 2004 a Draft Patents Bill was released for public consultation and submissions closed on 11 March 1995. A main goal of the proposed act is to tighten the procedures for granting patents, particularly by more rigorously determining what could be considered a valid invention. The previous 'presumption of patentability' has been removed and has been replaced with a 'balance of probabilities test'.

The Draft for Consultation Patents Bill ${ }^{102}$ Part 1:3:c specifically addresses: "Maori concerns relating to the granting of patents for inventions derived from indigenous

99 See id. at 910.

100 See Kadidal, supra note 76, at 401.

101 Boundaries to Patentability. See

http://med.govt.nz/templates/MultipageDocumentTOC_1451.aspx (3-17) (last visited Sept. 5, 2006).

102 Draft for Consultation Patents Bill http://www.med.govt.nz/upload/3358/draftbill.pdf (last Sept. 5, 2006). 
plants and animals or from Maori traditional knowledge ..." and 1:3:e specifically notes that the patent regime of NZ should take into account international developments.

This sets the stage for the most significant departure from current practice in New Zealand. According to patent law, an invention is: "novel if it does not form part of the prior art base." ${ }^{\prime 03}$ The prior art base is determined:

... in relation to an invention so far as claimed in a claim, means all matter (whether a product, a process, information about a product or process, or anything else) which has at any time before the priority date of that claim been made available to the public (whether in New Zealand or elsewhere) by written or oral description, by use, or in any other way. ${ }^{104}$

This introduced an absolute standard of novelty, not one just based on what is published in New Zealand. The revised legislation would clearly include the TK from India as part of the prior art. Unlike European legislation, TK is clearly in mind under the proposed legislation in New Zealand. The bill is still being debated to minimize the risk of unintended consequences. ${ }^{105}$

\section{Databases}

A TM database would put information in the public domain. ${ }^{106}$ It would allow patent examiners to identify what is novel in reference to TK. If a patent application were the same as what was recorded in the database, it would be denied. If the application was sufficiently different from what is recorded in the registry, than a patent could be granted. As one commentator has suggested: “... as long as the patent requirements of usefulness, novelty, and inventive step are strictly upheld by patent offices there is no reason for the traditional communities to feel exploited since if their knowledge were simply copied there would be no invention to patent." ${ }^{107}$ This statement of course assumes that the TK is question has been published. The database would offer a powerful platform for establishing prior art.

After the neem patent controversy, India, along with several other countries with extensive TM traditions, recognized the need for a central database that would record TM traditions that were often only available in oral form. This initiative was stimulated by a meeting of the South Asian Association for Regional Cooperation (SAARC), and it was envisaged that every country in the organization would prepare a TK database. The SAARC would pay for the infrastructure, but each country would fund the costs of the work itself. The overall structure of the database would be according to the international standards of TK as adopted by the intergovernmental committee of WIPO in 2003. Already in 2001, India had developed a system of clas-

103 See id. at Part $1 \mathrm{cl} \mathrm{6,} \mathrm{for} \mathrm{an} \mathrm{explanation} \mathrm{of} \mathrm{"novel".}$

104 See id. at Part $1 \mathrm{cl}$ 8, for an explanation of "prior art base".

105 See id. Topics Summary.

106 See Soutik Biswas, India hits back in 'bio-piracy' battle (2005), BBC News, http://news.bbc.co.uk/ go/pr/fr/- \1 \world/south_asia/4506382.stm) (last visited Sept. 1, 2006).

107 Dutfield, supra note 29. 
sifying TK resources that was adopted by the International Patent Classification (IPC). The IPC agreed to include about 200 sub groups of drugs derived from Indian medicinal plants. ${ }^{108}$ The fact that this is a regional effort is particularly important. TK does follow national boundaries.

This project gained particular popularity after the revocation of the patent on uses of tumeric. TK was taken seriously by patent granting authorities. In late 2005, the EPO was due to sign ${ }^{109}$ an agreement with the National Institute of Science Communication and Information Resources (NISCIR) in India so that the EPO could search a database of Indian TM. This would allow patent agencies to search the database for prior art. The NISCIR is negotiating with patent offices in the US, UK, Sweden, and Japan, and the NISCIR hopes that in the future there will be an international legal mechanism established by WIPO to protect TK. ${ }^{110}$

Some have suggested that the database could be used to further bio-piracy. The Traditional Knowledge Digital Library Task Force found 4,896 patents or applications based on 90 medicinal plants in the USPTO database. Apparently $80 \%$ of the references pertained to just seven Indian medicinal plants. The Task Force studied the patents and found that 360 of the 762 patents on medicinal plants that were granted by the USPTO could be categorized as traditional. ${ }^{11}$

The database may run into difficulty in that a patent examiner is trained in science, ${ }^{112}$ whereas the database would present TK. Literature can be understood on a number of levels, and allusions are not uncommon. Where are lines to be drawn in such situations? How would scientists go about searching a database of TK?

Despite these problems there have been calls to stop the project for fear that it might be too effective. Some in the pharmaceutical industry are concerned that by treating all medicines and healing remedies as IP, it would be difficult in the future to derive new medicines from plants. ${ }^{113}$ This would have an impact particularly on small to medium sized enterprises. Large corporations could isolate or synthesize slightly different active ingredients that would likely pass the novelty and inventive step hurdles.

108 See T.V. Padma Digital Library to protect indigenous knowledge http:/www.scidev.net/News/ index.cfm?fuseaction=readNews\&itemid=1840\&language=1 (last visited Sept. 5, 2006). The scope of the database according to this report is: "traditional medicine, foodstuffs, architecture and culture." It appears that the main focus of the database is TM, so it is quite logical that it would contain information about foodstuffs as well. It is more difficult to appreciate why architecture would be included, as this would apparently involve images that would use a proportionally tremendous amount of memory space in any database. Aspects of culture in general may well be difficult to organize and search.

109 The author could find no evidence that this agreement has been signed as of Sept 102006.

110 See Mary Ann Liebert Inc., EPO Takes Step Toward Blocking Patents on Traditional Medicines, 24 BIOTECHNOLOGY L. REP. 445 (2005).

111 Devinder Sharma, Digital Library Another Tool for Biopiracy (2002). http://www.mindfully.org/GE/ GE4/Traditional-Knowledge-Digital-Library-TKDL29may02.htm (last visited Sept. 1, 2006). The author also suggests that both WIPO and UNCTAD are eager to support a system that would legalize their monopoly positions in controlling TK. This seems an usually harsh assessment, as the systems would not directly involve these organizations.

112 Someone with understanding of TK should analyze the prior art to determine if the invention involves an inventive step. See N.S. Gopalakrishnan, TRIPS and Protection of Traditional Knowledge of Genetic Resources: New Challenges to the Patent System, 27(1) E.I.P.R. 14 (2005).

113 See Traditional Knowledge Digital Library Seeks to Prevent Biopiracy, http://sippi.aaas.org/ipissues/ updates/?res_id=618.) (last visited Sept. 5, 2006). See also J. Lancaster India Digitizes Age-old Wisdom, The WAShington Post, 8 Jan. 2006, at A22. The article also suggests that the Digital Library would be made available to foreign patent offices "at some point later this year". Id. 
The Workshop on Traditional Knowledge and Biological Diversity called for the suspension of registering TK. The USA has also raised the issue that medical research could be impeded with the formation of such a registry, and that it may be in violation of the TRIPS agreement. ${ }^{114}$ The latter assertion appears to be difficult to support.

From media reports, many proposed authors did not want to participate in a venture that could be damaging to their communities. ${ }^{115}$ There is also a general reticence of some to commit an oral tradition to writing. These groups worry that after publication they will lose control of their sacred or cultural property. At first the compilers will put materials on the database that have already been printed, although perhaps originally in a number of non-European languages. Later original materials will be collected from a number of sources. ${ }^{116}$ As is the case with much TK, it may be controlled by community members who may change the TK over time. There can thus be older static elements as well as newer elements attributable to an individual. A member of a 'traditional' community could enjoy copyright as an author on these new additions according to western standards, although under traditional law it may be the community as a whole that retains these rights.

\section{Fair Use}

The proposed TK database would cover a vast subject area. Increasing amounts of information, some of it perhaps appearing for the first time in written form, would be of interest to academics. ${ }^{117}$ Specialist academic attention could perform useful functions. Gaps in the information could be identified and faulty data could be corrected. The danger remains that if the database were simply produced by a small group of people and used by another select group it would be a self-pollinating system.

One option would be to 'code for fair use' by allowing some users - academics for example - to view material for a certain period of time, perform a certain number of searches on the database, or to extract a certain amount of material. The main problem is simple. The program restricting access would be, by necessity, complicated. It almost certainly would not anticipate the range of needs encountered by 'fair use' research. The other option is to appoint a controlling body that would act as a gatekeeper for the database. The unique circumstances of every case could be carefully accessed and bona fide fair use research could be used to improve subsequent versions of the database. Author representatives could be involved in controlling access by dis-

114 See Thomas J. Krumenacher, Protection for Indigenous Peoples and their Traditional Knowledge: Would a Registry System Reduce the Misappropriation of Traditional Knowledge? 8 MARQ. INTELL. PROP. L. REV. 143, 158 (2004).

115 See Lancaster, supra note 113, at A22.

116 See Biswas, supra note 106.

117 There are many proposals regarding the proposed database. While some state that only patent examiners will have access, others state it will be a resource for academics as well. Some form of digital rights management system is envisaged. See Caroline Ryan, Patent to protect ancient knowledge (2002) BBC News, http://news.bbc.co.uk/1/hi/in_depth/sci_tech/2002/boston_2002/1828438.stm (last visited Sept. 5, 2006). 
tributing electronic keys that would access encrypted work. ${ }^{118}$ This would likely satisfy most contributors to the database.

\section{Is the Database Project Viable?}

A TK database could be a powerful tool for a patent office and an effective research tool for unauthorized users. Assuming the latter issue can be resolved (a complicated assumption), a fundamental issue arises in control. Local indigenous communities are not likely to have the skills required to manage a database by themselves. They would require the control and coordination of central authorities who may or may not understand their particular culture. All things considered, the project appears to be both controversial and expensive.

\section{DISCLOSURE OF ORIGIN}

There is considerable debate about disclosure of origin (DO) requirements. ${ }^{119}$ DO, making patent applications open to the public, is a central tenant of India's proposal to harmonize TRIPS and the CBD. ${ }^{120}$ Both DO and public access to patent applications focus on the same goal, to prevent the misappropriation of genetic material. International agreements provide for the protection of geographical terms but do not consider DO. TRIPS article 27.1 stipulates what is patentable subject matter; it makes no mention of the origin of resources. A patent could be obtained using 'bio-pirated' genetic material. While criminal or civil law may or may not provide a remedy, the patent would still be valid. Article 27(3)(b) of TRIPS states that members may exclude plants and animals from patentability, although protection for plant varieties must be provided either by patents or a sui generis system or by a combination of both. Disclosure of origin was clearly not a major issue facing the framers of TRIPS, but it is an increasing interest as the norms of bio-piracy are established.

Bio-piracy is a term used to describe the practice - often by western companies - of patenting products based on TK or genetic resources without providing compensation or recognition. It is a complicated issue. ${ }^{121}$ There are problems associated with the term itself:

... an examination of specific cases in which traditional knowledge is commercialized reveals that it is not always easy to determine exactly the nature and extent of the inequity. Imprecise references to the technical language and concepts of intellectual property law

118 See Dan L. Burk and Julie E. Cohen, Fair Use Infrastructure for Copyright Management Systems, Georgetown University Law Center 2000 Working Paper Series http://papers.ssrn.com/paper.taf? abstract_id=239731 (last visited Sept. 5, 2006).

119 See Dominic Keating, Access to Genetic Resources and Equitable Benefit Sharing Through a New Disclosure Requirement in the Patent System: An Issue in Search of a Forum, 87 J. PAT. \& TRADEMARK OFF. SOC'Y 525 (2005).

120 See Kruger, supra note 40.

121 See David Conforto, Traditional and Modern Biopiracy: Redefining the Biopiracy Debate, 19 ENVTL. L. \& LiTTIG. 357-358 (2004). 
sometimes make it difficult to identify exactly what the practical problems are, and may unnecessarily alienate one interest group or another, such as industry, intellectual property experts, and indigenous and local organizations. ${ }^{122}$

According to US law, a patent cannot be obtained if the person did not: "“... invent the subject matter sought to be patented." ${ }^{123}$ Perhaps the best example where an applicant has not fully disclosed the origin of the material is in the case of the Ayahuasca patent. This plant was used in rituals by South American Indians for a long period of time. The applicant claimed that the plant was new and unique. However, it was found growing in a domestic garden in South America. ${ }^{124}$ According to local tradition, the plant can only be taken as part of a ceremonial drink administered by a Shaman. Acting through the Center for International Environmental Law (CIEL) on behalf of the Coalition for Amazonian Peoples and Their Environment, the USPTO re-examined the patent because previous publications described the plant. The patent was later reinstated. $^{125}$ It is notable here that the legal action was handled by a collective body with resources that allowed it to be at least partially successful.

This and other cases of the failure of the patent system to require DO has led some to suggest that a sui generis system should be used. There are two general theories about how such a system should operate. It could be a mandatory requirement to issue a patent, or it could be enforced by other means. With a DO scheme in place, it would be required to disclose the source of any genetic resources or TK used in an invention. There would also be a requirement to provide evidence that the right holder gave permission for its use. Permission would be more detailed than a simple contract, as proponents hold that it is only informed consent that would qualify. It would be likely this would be evidenced by some benefit sharing agreement.

To date, statutes passed by the Andean Community and Costa Rica require that patent applicants supply the patent office with the origin of genetic resources used. If appropriate, a demonstration of prior informed consent either from relevant government authorities or from indigenous communities is also required. ${ }^{127}$ From a patent law perspective, it would be difficult for a mandatory scheme to comply with national legislation and international treaties. While it is difficult to pinpoint the genesis of these viewpoints, the CBD played a major role in solidifying the arguments. Article 15.4 of the CBD states that an agreement should be concluded on mutually agreed terms.

122 David R. Downes, How Intellectual Property Could be a Tool to Protect Traditional Knowledge, 25 COLUM. J. ENVTL. L. 264-265 (2000).

12335 U.S.C. \& $102(\mathrm{f})$.

124 U.S. Plant Patent No. 5,751 (issued June 17, 1986).

125 See de Carvalho, supra note 7, at 55. The author noted that a particular focus of the opposition to the patent on Ayahuasca was the fact that disclosure was offensive to their beliefs.

126 See World Trade Organization, The Relationship Between TRIPS Agreement and the Convention on Biological Diversity and the Protection of Traditional Knowledge, IP/C/W/356 http://docsonline. wto.org/gen_search.asp/?searchmode=simple (last visited Sept. 1, 2006). The Permanent Mission of Brazil at the WTO presented a proposed amendment of TRIPS, along with China, Cuba, the Dominican Republic, Ecuador, India, Pakistan, Thailand, Venezuela, Zambia and Zimbabwe.

127 See the Common Regime on Access to Genetic Resources, Andean Decision No. 391, Andean Community of Nations (August 16, 1996), http://sice.oas.org/trade/JUNAC/decisiones/DEC391e.asp (last visited Sept. 5, 2006). The Andean Community counts Bolivia, Colombia, Ecuador and Peru as members. The Biodiversity Law (No. 7788) of Costa Rica enacted on May 271998 can be found at http:// www.grain.org/docs/costarica-biodiversitylaw-1998-en.pdf (last visited Sept. 5, 2006). 
Article 15.5 of the CBD raises the issue of prior informed consent. The CBD adopted the Bonn Guidelines ${ }^{128}$ in April 2002. The Guidelines provide a voluntary framework that would improve DO requirements. While not binding, the Guidelines are being considered by WTO and WIPO committees. ${ }^{129}$ DO requirements are a central feature of contracts that cover prospecting for genetic resources.

\section{PROSPECTING AGREEMENTS}

There have been several instances where companies have collected TM, both biological material and TK, under a contract with the government of the source country. ${ }^{130}$ This in effect acknowledges origin, and compensates the right holder. It is very difficult to estimate the value of biological material, as well as TK, in advance. Given that these contracts will exist between multinational corporations and less developed countries, multinationals have a bargaining advantage that may lead to the undervaluation of TK. In contrast a patent:

... allows its holder to accept the risk that its value will change over time. Patent rights would give LDC's [Less Developed Countries] the freedom to wager that their biodiversity resources will become more valuable over a longer time horizon. Denied this alternative, LDC's will be forced to accept the lower up-front offers a contractual natural-resource exploitation brings. ${ }^{131}$

Despite some pessimistic appraisals, there is no evidence that prospecting agreements led to exploitative agreements. Perhaps the best known prospecting agreement was between Merck and the National Biodiversity Institute, an organ of the Costa Rican government. Merck paid an initial fee of about 1 million US dollars ${ }^{132}$ plus an undisclosed royalty fee. ${ }^{133}$ The territory explored is limited but within that area both the government and indigenous peoples will assist the company in collection. Merck will hold title to all patents that result in products developed from the agreement. The agreements were concluded before the CBD and the Bonn Guidelines were established, but many of the same concerns were addressed by the Merck agreement. Part of the initial fee was invested in national parks, scientific training, and in conducting a biodiversity inventory. Technology transfer, as provided for in the agreement, made work in the source country more effective. At the same time, royalty payments would encourage further conservation efforts. ${ }^{134}$ There was no mention of the rights of indig-

128 Bonn Guidelines on Access to Genetic Resources and Fair and Equitable Sharing of Benefits Arising out of their Utilization, http://www.biodiv.org/doc/decisions/COP-06-dec-en.pdf (last visited Sept. 5, 2006).

129 For a general discussion, see Michal Gollin, Feasibility of National Disclosure of Origin Requirements, http://www.iucn.org/themes/pbia/documents/trade-docs/gollin.pdf (last visited Sept. 5, 2006).

130 There is also debate if US companies should pay for biological resources taken from public lands. See Sandra Bourgasser-Ketterling, Bioprospecting on Public Lands: Should Private Companies Compensate the Government for their use of Public Land Resources, 8 J.L. \& POL'Y 481 (2000).

131 Shayana Kadidal, Plants, Poverty, and Pharmaceutical Patents, 103 YALE L.J. 232 (1993).

132 See Birds and Bees, THE ECONOMIST, May 30, 1992, Survey Section at 15.

133 The amount of the royalty has been estimated at $1-3 \%$ of any product that results from the agreement. See Pharmaceutical Companies Go "Chemical Prospecting” for New Medicines, PHARMACEUTICAL BUS. NEWS, Aug 21, 1992, available in LEXIS, Nexis Library, PBNWS File.

134 See Scott Shahverdian, Bioprospecting Success, Failures and Viability as a Global Regime, http:// www.colby.edu/personal/s/smshahve/bio\%20web\%20page\%20final.htm (last visited Sept. 5, 2006). 
enous communities in the agreement. The assumption would be that there would be a 'trickle down' effect, but this may not be the case in practice. Money given to the central government may stay there.

Later agreements addressed this issue by paying special attention to local needs. The most cited example is Shaman Pharmaceuticals, a company founded in 1989 in California. The name clearly suggests the scope of the company, which aimed to take TK from local communities under fair prospecting agreements. Direct payments were made to support pressing needs such as clean drinking water, roads, and health care. Medium term needs were addressed through technology transfer and training. Long term benefits were regarded as royalty payments. Fifty percent of all royalties apparently went back to indigenous communities and the other half went to the local government. ${ }^{135}$ Not all observers were pleased with Shaman's business practices. The Coalition Against Biopiracy has proposed the company to be a "Captain Hook Award Nominee" for, as the name suggests, appropriating indigenous knowledge.

In a short description they suggest these activities "brazenly dredge the public domain" for patentable information. Company research on Sangre de Drago, a South American plant, was a particular source of contention. They awarded Shaman "The Forked Tongue Platter" for purchasing fermentation technology from Bayer that would potentially reduce the need to purchase plants from local suppliers. ${ }^{136}$

The value of Sangre de Drago (Croton lechleri) was a hotly debated issue. Shaman filed for two US patents, one for Provir, an oral medication against a childhood respiratory disease, and Virend, an anti-herpes medication. The company held that not only would it make a profit, but the local community, as well as biodiversity in general, would benefit. Integrating local ethnobotanical information was critical in finding these drugs. As a general figure cited in Shaman's literature, one pharmaceutical would be identified from 10,000 randomly screened plants. Shaman contended that by using local knowledge they could obtain a drug in one of two plants. ${ }^{137}$ Yet these two patents were the heart of the issue. One author has held that:

... the curative powers of Sangre de Drago is in the public domain. While knowledge about many other traditional remedies is strictly guarded, in this case all groups living in the Amazonian area - indigenous peoples, racially-mixed populations, settlers, and even tourists share it. The plant's chemical composition and ethnobotanical uses have been published several times: hardly a 'trade secret'. This makes Shaman's claim of 'novelty' for the two products it has developed from local knowledge about Sangre de Drago more than questionable. $^{138}$

135 See Roger Alex Clapp \& Carolyn Crook, Drowning in the Magic Well: Shaman Pharmaceutical and the Elusive Value of Traditional Knowledge, 11 JOURNAL OF ENVIRONMENT \& DEVELOPMENT 79 (2002).

136 See Biopiracy: Captain Hook Award Nominees, http://twm.co.nz/CptHook.htm (last visited Sept. 5, 2006).

137 See Steven R. King \& J. Carlson Thomas, Biocultural Diversity, Biomedicine and Ethnobotany: The Experience of Shaman Pharmaceuticals, 20:3 INTERCIENCIA 134 (1995). While the figure that one in two plants known to 'Shamans' can result in a pharmaceutical appears overly optimistic, particularly as the company did declare bankruptcy, it is clear that the search for drugs is narrowed considerably from the figure of one in 10,000 in a 'blind' screening.

138 Viki Reyes, Seedling, QuARTERLy NewsLETTER OF Genetic Resources InTERNATIONAL, March, 1996, http://www.grain.org/seedling/index.cfm?id=150\&print=yes (last visited Sept. 5, 2006). 
This statement does not seem to express any solid reasoning as to why the patents should not be granted, as there is a clear leap between general knowledge and particular application as a drug. The natural substances used in Aspirin had been known for thousands of years before Bayer acquired a patent for their drug. This did not act as a bar to acquiring a patent. There is no requirement that an invention has to be a trade secret in order to be patented.

Shaman declared bankruptcy in 1991; much speculation as to the cause of bankruptcy followed. The business model would at first appear to have so many positive aspects, not least of which is the desire to help protect the environment. Some have suggested that the model, while viable at the time, signals: “. . . the fall of 'ethnobotany' as a viable economic pursuit. As technological advances allow for hundreds of thousands of genetic samples to be screened each day, the indigenous knowledge Shaman worked so hard to protect seems to be becoming obsolete." ${ }^{139}$ This statement seems to cast doubts upon the viability of TM to provide useful information. Indeed, genetic information is a discovery and cannot, in itself, be patented, much less turned into a marketable drug. It seems the real reason Shaman lost so much money is that there were unrealistic expectations as to the outcome. Large pharmaceutical companies are prepared to continue to investigate drugs derived from TM, and their budgets can be many times what a smaller firm could organize. It may be that indigenous knowledge remains as important as ever. The failure of one company, and perhaps a particular business model, may not be indicative of the market in general.

The saga of Shaman Pharmaceuticals does highlight one important consideration. Leaving aside accusations of bio-piracy, if the company did indeed have the best interests of all parties involved, the end result is that patents have been filed in the name of a company that no longer exists. These patents will eventually enter the public domain, but before that time, it is likely that the community that assisted in the drug development will not be compensated. No one intended this result. Future agreements must take precautions.

There has been much academic interest in bio-prospecting agreements. ${ }^{140}$ However, according to some academic observers, the pharmaceutical industry may be moving away from medicinal plant screening for drug development. Over the past decade there has been little new discovery of commercial products from plants. The continued controversy over the use of national biological resources may have played a role in this shift. In part, this has prompted a shift to marine exploration, where natural products are not subject to IP constraints. ${ }^{141}$ Marine exploration can take place within nationally controlled coastlines. If this is the case, there may still be claims to these materials under the CBD. Prospecting agreements could very well extend into the seas.

If current IP constraints makes drug screening difficult, this should be reflected in prospecting agreements, which would offer less up front payment in return for a greater share of profits. Benefit sharing carries with it the risk that profits would be

139 Shahverdian, supra note 134.

140 See Daniel M. Putterman, Model Material Transfer Agreements for Equitable Biodiversity Prospecting, 7 COLO. J. INT'L ENVTL. L. \& POL'Y 150 (1996).

141 See Bodeker, supra note 11 at 794. 
less than projected. Prospecting agreements governed by contract law allows the parties to draft their own agreement according to their wishes. It therefore emerges as a flexible method of protecting TM, as long as all the parties are aware of the issues involved.

\section{GEOGRAPHICAL INDICATIONS}

India has proposed that in order to harmonize the CBD and TRIPS, geographical indications (GI) should be expanded to protect more forms of TK. They clearly envisaged that a strong GI system would have hindered the well known neem patent in the USA. In practice, however, it is unclear how this would have been the case. ${ }^{142}$ TRIPS article 22 outlines that geographical indications: “. . . identify a good as originating in the territory of a Member, or a region or locality in that territory, where a given quality, reputation or other characteristic of the good is essentially attributable to its geographical origin." TRIPS article 23 outlines additional protection for wines and spirits. This method offers a way that rights could be maintained for an unlimited amount of time. It does not confer a monopoly right on a few individuals. Geographical indications: "... reward producers that are situated in a certain region and that follow production practices associated with that region and its culture and customs. They are designed to reward goodwill and reputation created or built up by a group of producers over many years, and in some cases over centuries."

Perhaps best known for the protection of regional foods, such as wine or cheese, GI have been proposed as a method for protecting TK. It is uncertain how effective this would be in practice. ${ }^{144}$ Most GI are French, where special attention is paid to products that are distinctive due to a combination of cultural and territorial factors. Regional associations have established standards for particular products. National laws' enforcement upholds the integrity of the geographical indication. ${ }^{15}$

A more relevant example, used to protect indigenous products, is American Indian arts and crafts. Particularly in the case of Southwestern tribes, non-native producers were using inauthentic methods and materials to make products put forth as genuine. The state of New Mexico passed the Indian Arts and Crafts Protection Law that gives retailers the duty of determining if a product was made by a Native American by hand. Somewhat controversially, there is no test to determine whether an item was made using traditional methods. Only after examination by a retailer can it then can bear a distinctive label stating it is an authentic, hand made Indian product. ${ }^{146}$ As is clear with the latter point, it would be quite difficult for a non-specialist to determine if the

142 See Kruger, supra note 40.

143 See Downes, supra note 122 at 272.

144 See Tomer Broude, Taking Trade and Culture Seriously: Geographical Indications and Cultural Protection in WTO Law. 26 U. PA. INT'L ECON. L. 633 (2005).

145 See L. Berard and P. Marchenay, Tradition, Regulation, and Intellectual Property: Local Agricultural Products and Foodstuffs in France, in VALUING LOCAL KNOWLEDGe 230, 238 (1996).

146 See Sandra L. Pinel and Michael J. Evans, Tribal Sovereignty and the Control of Knowledge, in INTELLECTUAl PROPERTy Rights For Indigenous PEOPles: A SOURCE BOOK (1994). 
product was made using traditional methods. However, the law acts as a barrier to imitation.

GI have a limited role for protecting TM, if it is clear that certain medicines originate from a particular region. In order to make geographical indications an efficient (and accurate) form of protection there needs to be a high level of appreciation, both in the public and in the examining authorities. In the case of French food products, one could find such expertise widely. There is still a debate regarding the correct method of manufacture for American Indian arts and crafts. A very small group of specialists have knowledge of this area, and in order to make a definitive statement there would have to be a specially constituted committee. While buyers of art may be satisfied with certification by a retailer, the situation with drugs is more complicated. There needs to be a high level of organization to make protection feasible.

While at first sight protection using GI appears to be simple, it may be - in practice very complicated. Committees to establish standards must be formed, and national laws must be made to enforce these standards. The system may be applicable to well established TM systems, such as in China, but may have limited coverage in other TM systems.

In addition, a patent protects an idea, not the products themselves. Patented TM could be made under license by a concern unconnected with the inventor. Even a group with limited production facilities could benefit from an invention if it held a patent. GI best suit a more extensive operation.

\section{TRADEMARKS}

Trademarks are, according to the TRIPS article 15: "Any sign, or any combination of signs, capable of distinguishing the goods or services of one undertaking from those of other undertakings ..." WTO members are required to protect trademarks via registration. In addition, TRIPS article 23 states that members must provide legal means for preventing registration of trademarks that mislead the public about geographical origin.

Trademarks are similar to GI. The US provides protection for GI though the trademark system, where they can be registered as a collective mark. A clear linkage with the place of origin must be demonstrated. ${ }^{147}$ In the US there are hundreds of foreign GI's protected through the GI certification system. Some examples are Colombian coffee and Darjeeling tea from India. ${ }^{148}$ Both the GI's and the trademarks are eligible for relief under the Federal Trademark Act. ${ }^{149}$ In the EU, GI's cannot be sold, but any producer in a certain region may use a specific GI. Individual companies are allowed to develop their own 'sub brands' within the system. ${ }^{150}$

147 Marianna Rubio \& Elizabeth M. Williams, Food, Geography \& the Law, 54 La. B.J. 12 (2006).

148 Bruce A Babcock \& Roxanne Clemens, Geographic Indications and Property Rights: Protecting Value-Added Agricultural Products, Midwest Agribusiness Trade Research and Information Center (MATRIC), Briefing Paper 04-MBP 7. May 2004 at page 2.

14915 U.S.C. $\S \S 1051$, et seq.

150 See Babcock \& Clemens, supra note 148, at 4. 
The use of trademarks under either the US or EU model suggests a high level of organization:

In particular, the necessary registration of a collective mark, as well as the management of a trademark once obtained, involves financial investment that may constitute an obstacle for indigenous peoples. In addition, the success of a trademark also depends on knowledge about the best marketing strategies, including the establishment and control of distribution channels and the devise of proper public relation measures. ${ }^{151}$

As with GI protection, trademarks do not emerge as a powerful tool to protect TM. There must be a registration system that would act as a primary barrier. Perhaps more significant is that a trademark is useful when products are brought to market. This implies a level of complexity that few indigenous groups possess. In contrast, a patent could be owned by a group that may be unable to market a product. In sum, trademark protection appears to be useful only in limited circumstances, such as might be the case for some Chinese TM.

\section{TRADE SECRET PROTECTION}

Indigenous communities may lack the resources to successfully bring a patent application to fruition. The process is far from a simple administrative procedure; it requires access to legal resources to prepare the application. As well as costs for the application itself, there are legal issues that can arise after the grant. There can be opposition to granting the patent as well as litigation over infringement. It is also clear that with much TK, there is difficulty in determining the inventor. Other groups may possess similar information, which would make the application by one group potentially unfair. A group may not want to share their information. After the expiry of a term of protection under a patent, the information becomes public. ${ }^{152}$

Because of these considerations, some have suggested that trade secret laws could be used to supplement or even supplant patent protection of TK:

While there is excessive attention being placed on patents and their restrictive nature against the protection of traditional knowledge, trade secrets have not been adequately exploited by national institutions and local peoples to protect the knowledge. It is however known that traditional peoples have used - and possibly continue to use - trade secrets to protect their knowledge. However, this form of protection of traditional knowledge is generally not institutionalised: institutions to safeguard trade secrets of indigenous and local peoples are either weak or absent in most countries. ${ }^{153}$

According to the author above it is essential that national governments enact laws that allow trade secret law to apply to TK. Yet to date there is little consensus - unlike the

151 Silke von Lewinski, Symposium Traditional Knowledge, Intellectual Property, and Indigenous Culture Articles, 11 CARDOZO J. INT'L \& COMP. L. 764 (2003).

152 See Stevenson, supra note 63 at 1152.

153 Mugabe, Intellectual Property Protection and Traditional Knowledge, paper prepared for WIPO, (December 1998), accessible via the homepage of the African Centre for Technology Studies available at http://www.acts.or.ke (last visited Sept. 5, 2006). 
case for patents - regarding how trade secrets should be protected on an international level. It was only when TRIPS came into effect in 1994 that trade secrets were recognized in international agreements. ${ }^{154}$ Until 1996, the US did not have a federal trade secret law. In 1996 the Economic Espionage Act passed, which gives a federal criminal remedy for the misappropriation of trade secrets.

There are three basic requirements for trade secret protection which sets a high hurdle for TK and TM to pass. The first requirement is that the information must be a secret, the second is that it have commercial value because it is secret, and the third is that reasonable efforts were made to keep the information secret. The scope of the protected information can be broad. The courts will place particular emphasis on the conduct of the parties rather than on the subject matter. ${ }^{156}$ The main positive feature is that protection does not require any government involvement or registration. Particularly in the case of TK, which is known to a small group of people, the definition of secrecy is of critical importance. Secrecy does not have to be absolute. It is possible to disclose the information on a 'need to know' basis as well as under a confidentiality agreement. $^{157}$ This, however, appears to be a situation more suited to a controlled business environment rather than one involving TK.

While at first trade secret protection would appear to be ideal, there are several significant problems. A large amount of TK could be appreciated as being in the public domain. Western research, as well as disclosure to other groups, quickly run afoul of the first requirement. Reasonable steps to protect secrecy, the second criteria, would be difficult to demonstrate in most cases. Without reasonable proof that efforts were made to maintain secrecy, it is unlikely a court would recognize a trade secret. ${ }^{158}$ As noted before, there are few nations that have a well developed legal structure to protect this kind of information. When TK is considered, this situation is even more unclear. Perhaps even more significant, trade secret protection is generally considered weaker than patent protection. It does not protect against reverse engineering or independent development. ${ }^{159}$ According to the Uniform Trade Secret Act, the acquisition of the known product must be by honest means if reverse engineering is to be considered lawful. ${ }^{160}$

On another level, the reason why trade secret protection is not usually encouraged is that it can stifle the flow of information. ${ }^{161}$ However, it can offer complete control of the information for a long period of time. Particularly for pharmaceuticals, a moral argument could be made that information with the potential to help the public should

154 See Stevenson, supra note 63 at 1153.

155 The Economic Espionage Act 199618 U.S.C. $\S \S 1831-1839$. A detailed discussion of the Act is available at http://cybercrime.gov/ipmanual/08ipma.htm\#VIII.B.2.c (last visited Sept. 5, 2006). According to 18 U.S.C. $\S 1832$ the Act applies to trade secrets that are related to or included in a product that is produced for or placed in interstate or foreign commerce.

156 See Donald S. Chisum \& Michael A. Jacobs, Understanding Intellectual Property Law $\S 3 \mathrm{C}(1992)$.

157 See Michael J. Hutter, Protecting Trade Secrets: Legal Theories, in PROTECTING TRADE SECRETS 1989, at 9,15 n43 (1986).

158 See Jacoby and Weiss, supra note 10, at 101.

159 See CHISUM \& JACOBS, supra note 156.

160 Unif. Trade Secret Act cmnt. to $§ 1$ (amended 1985), 14 U.L.A. 438.

161 See Jacoby and Weiss, supra note 10, at 101. 
not be secret. It has been a common refrain that the patenting process is inimical to many conceptions of how TK should be regulated in traditional societies. Trade secret protection - the limiting of disclosure - would appear to be closer to a 'state of nature' than patents. Yet in both systems, the profit from the information may be restricted or may be distributed in any way that the group chooses. However, in trade secret law the information must be secret.

In contrast, patents allow non-commercial research to take place. After the period of protection expires, the information will enter the public domain. One is left to wonder what the consequences to all of human society would have been if the information from several plant derived 'wonder drugs' of the early part of the last century were still trade secrets.

Specifically in the case of pharmaceuticals, it appears unlikely that a public authority would allow a drug to be marketed without having a detailed understanding of the methods and materials used in its manufacture. Finally, as with GI and trademark protection, trade secret protection is ideal for a well developed commercial concern. It may be useful for protecting other forms of TK, but for TM, it appears totally unsuitable.

\section{CHINA}

\section{Statutory Protection}

The legal methods of protecting Traditional Chinese Medicine (TCM) are distinctive. The reasons for this revolve around the peculiarities of TCM. The result is that while China has specific legislation, it might not be an appropriate model for other nations to follow. There has traditionally been little regulation of TCM in China, although the last several decades have witnessed increasing legislation. In 1992 the Regulations on Protection of Traditional Chinese Medicines (effective 1 January 1993) ${ }^{162}$ was enacted. The aim of the law is to encourage research and development of new varieties of Traditional Chinese Medicine (TCM). The law is not applicable after patent rights have been applied for. ${ }^{163}$ It is therefore a sui generis system designed to operate in conjunction with patents.

The Chinese regulation stipulates that: "This Decree is applicable for all varieties of traditional Chinese Medicines produced and/or prepared within the territory of China, including traditional Chinese proprietary medicines ...". ${ }^{164}$ The Chinese regulation does not specifically address the issue of TK. It envisages that the IP rights would be vested either in an individual or corporate structures. There is no provision for a community to own rights in TCM. The regulation introduced graded protection of stable

162 Regulations on Protection of Traditional Chinese Medicines Article 2, (Promulgated by Decree No. 106 of the State Council of the People's Republic of China on October 14, 1992).An English translation is available at http://cq.netsh.com/bbs/751605/html/tree_5837217.html (last visited Sept. 5, 2006).

163 See id. art 2.

$164 \mathrm{Id}$. 
varieties of traditional Chinese Medicines (TCM), as Article 3 makes clear. The insertion of the word 'stable' here suggests that the mixtures must be replicable, and that there must be complete disclosure. This may present some difficulty to practitioners of TCM, as some remedies may contain secret materials. There are to be two grades of protection, Grade 1 and Grade 2. Briefly, the former must have special therapeutic results to a given disease. ${ }^{165}$ The latter group must have "noticeable therapeutic results to a given disease." 166 Article 13 stipulates that: "The ingredient and formulae, and its technical know-how of the preparation for varieties under Grade 1 protection shall be


not apply to Grade 2.

\section{Patent Law}

There has also been recent change in China's patent laws to include TCM. This is allowed under TRIPS 27.1, which states patents: “... shall be available for any inventions, whether products or processes, in all fields of technology, provided that they are new, involve an inventive step and are capable of industrial application." The Patent Law of the People's Republic of China ${ }^{168}$ did not previously allow TCM to be patented. Before January 1 1993, methods used to prepare drugs could be patented, but products and usage could not. After this date, it was possible to protect products, methods and usage. There have been a number of filings regarding TCM. Since 1992, when the patent law was amended, there have been an average of 1400 cases per year. ${ }^{169}$ Patents may be granted for inventions, utility models, and designs. ${ }^{170}$ TCM would be protected as an invention. Article 22 of the Chinese Patent Law states that any invention must possess novelty, inventiveness and practical applicability tests. The test for novelty means that no identical invention has been disclosed in publications in China or abroad, or has been publicly used or made known to the public by any means. ${ }^{171}$ This is perhaps the most difficult hurdle of Chinese TM to cross, as there has been a wealth of literature devoted to TM in China spanning an enormous period of time. A similar observation could be made on the issue of public use. Remedies that have been essentially protected as a trade secret could still be patented. Commonly known treatments could not be.

165 See id. art 6.

166 Id. art 7.

167 See id. art 13.

168 Patent Law of the People's Republic of China, adopted at the $4^{\text {th }}$ Meeting of the Standing Committee of the Sixth National People's Congress on March 12, 1984; amended in accordance with the Decision of the Standing Committee of the Seventh National People's Congress on Amending the Patent Law of the People's Republic of China at its $27^{\text {th }}$ Meeting on September 4. 1992, see http:///sipo.gov.cn/ sipo_English/flfg/zlflfg/t20020327_33872.htm (last visited Sept. 5, 2006).

169 See generally Yongfeng, Zheng, The Means and Experiences of Patent Protection of Traditional Medicine in China 3-11. http://r0.unctad.org/trade_env/test1/meetings/delhi/Countriestext/CHINAspeech.doc (last visited Sept. 5, 2006).

170 See Patent Law, supra note 81, art. 2.

171 See id. The tests for inventiveness and practical utility are also covered in Art 22. 
Article 25 of the Chinese Patent Law states that methods for the diagnosis or treatment of diseases cannot be patented. A new use for a known drug is patentable. According to a patent examiner from the Patent Office of the Peoples Republic of China, ${ }^{172} \mathrm{a}$ medicine may be composed or prepared from a mixture of several herbs as long as no identical method has been published before the application. This mixture can be said to be newly created. A drug may also be made from a substance not previously known. In the latter case, evidence must be submitted regarding medical effectiveness. A medicine may also be composed from several known herbal medicines if the constitution or ratio has been changed so that the new mixture has new properties, such as increased effectiveness or fewer side effects.

TCM has incorporated scientific techniques, which makes determination of novelty more straightforward. ${ }^{173}$ A good example is a "Technique of Preparation of Ripe Rhubarb by Heat Pressing." This involves isolating the active ingredients from rhubarb by heating at high pressure with the use of supplementary materials. ${ }^{174}$ While rhubarb is well known, the method of extraction was the invention. In another case, the invention relates to the method of delivery. In the patent titled "Injection of Root of Red-rooted Salvia" the patent relied upon a form of the drug that could be easily used in a clinical environment because it could be injected. ${ }^{175}$

In 2004, the Chinese Ministry of Science and Technology has made the modernization of TM one of the 12 main focal points of its current 5-year plan. An entire technology park in Houzhou has been devoted to the scientific study of Chinese Medicine. ${ }^{176}$ Most of the investment occurs in state institutions. Much of the impetus arises from fears that foreign pharmaceuticals will dominate the Chinese market. ${ }^{17}$

The TK content in TCM is not easy to define. On one hand there is a philosophical basis, while on the other hand TCM is increasingly being integrated with western medical practices. There may be less of a focus on conserving indigenous practices. This is in contrast to such countries as Thailand or the Philippines, which are exploring many possibilities besides the patent system. ${ }^{178}$ It may be that Chinese legislators find patents a more formidable form of protection. Considering that TCM has been integrated with scientific techniques, patents may be suitable for China and less so for other nations.

172 See Yongfeng, supra note 169.

173 See Liu, supra note 27 at 198-99. She lists five examples of patents that overcome the novelty requirement by using new techniques or methods. Her example numbers 1 and 5 are used here.

174 U.S. Patent No. 85100957, http://211.152.9.47/sipoasp/zljs/hyjs-yx-new.asp?recid=85100957\&lexin=0> (last visited Sept. 5, 2006).

175 U.S. Patent No. 94114040.7 , http://211.152.9.47/sipoasp/zljs/hyjs-yx-new.asp?recid=94114040.7.X\&lexin=0> (last visited Sept. 5, 2006).

176 See Paroma Basu, Trading on Traditional Medicines, 22:3 NATURE BIoteChNology 263 (2004).

177 Teresa Schroeder, Chinese Regulation of Traditional Chinese Medicine in the Modern World: Can the Chinese Effectively Profit from One of Their Most Valuable Cultural Resourcs? 11 Pac. Rim. L. \& Pol'y J. 687 (2002).

178 See Benjamin Liu, Past Cultural Achievement as a Future Technological Resource: Contradictions and Opportunities in the Intellectual Property Protection of Chinese Medicine in China, 97 U.C.L.A. PAC. BASIN L.J. 86 (2003). 
The statutory protection of TCM appears to offer an alternative in cases where scientific techniques are not integrated into TCM. There is apparently no need to fully characterize the drug, beyond being a stable mixture. The main focus is on clinical effectiveness. This form of protection appears to be much easier and less expensive to obtain than a patent. The Chinese example, however, shows that patent protection for TCM is still widely used and is growing in popularity. There is no doubt wide scale public acceptance of patents that a statutory system would find hard to match.

\section{A Database of Traditional Chinese Medicine?}

While southeast Asian countries such as India are enthusiastic about the establishment of database protection of TM, China does not seem to be moving in that direction. It is possible that given their current level of protection, via patents and the regulation of 1992, there is adequate protection and there is no need for a database. On the other hand, there are a number of factors that make a TCM database a very different undertaking from southeast Asia. One of the most obvious factors is language. For instance, China, Korea and Japan have a partially shared history in the development of TM. The result is that there can be the same formula titles used for traditional remedies, yet these will be pronounced differently in all three countries. It is difficult to communicate precise information about some aspects of TM given this level of uncertainty. ${ }^{179}$ The titles of TCM as expressed in Chinese characters have an ideographic meaning as distinct from a phonetic one as in an alphabetic system. When Chinese characters are translated into English directly - without explanation - a scientist would not understand their meaning. Many words indicate not only specific herbal materials and effectiveness but also expressions familiar only to Chinese culture. The problem is particularly acute with remedies involving multi-herb formulations. ${ }^{180}$

A recent attempt to classify TCM into a database involved seven distinct groups of information: 1. A systematic botanical description; 2. Herbal formulae with bibliography; 3. Diseases or symptoms treated; 4 . Traditional processing methods to remove toxic ingredients; 5 . Chemical structures of ingredients; 6 . Safety and toxicity data; and 7 Clinical reports of interactions with western drugs. ${ }^{181}$ While some of this information is relevant only when using these drugs, other aspects are essential when determining prior art for the purposes of a patent. Items 1-5 are essential, while safety items 6 and 7 are less of a concern at that stage. The authors did note that they had particular difficulty in translating the titles of the formulae as well as interpreting the symptoms and diseases as they were described in the literature.

While several of these issues arise for any proposed TM database, it appears that the situation for TCM and similar systems make preparing such a database difficult and

179 See J. Park, H.J. Lee \& E. Ernst, What's in a name? A systematic review of the nomenclature of Chinese medical formulae 30 AM J CHIN MED 419 (2002).

180 See M.Q. Zhang, A treatise on the standardization of prescription's name, in EXPERTS MEETING FOR THE STANDARDIZATION OF TITLES OF CHINESE PRESCRIPTIONS 33, 39 (I.M. Chang ed. 1996).

181 Yeong-Deug Yi \& II-Moo Chang, An Overview of Traditional Chinese Herbal Formulae and a Proposal of a New Code System for Expressing the Formula Titles 1 EVIDENCE-BASED COMPLEMENTARY AND Alternative Medicine (ECAM) 125 (2004). 
time consuming. Chinese laws give enough scope for practitioners of TCM to protect their own creations. Patents are preferred to databases to define the prior art.

\section{FLEXIBILITY OF THE PATENT SYSTEM?}

There are some commentators who find that the entire patent system is inflexible and unsuitable to protect TM. ${ }^{182}$ History does not support this viewpoint. A good example is the evolution of the original conception of a patent, which was designed to secure the individual's rights. This has changed over time so that patents are now owned by large companies, particularly in the pharmaceutical industry. There are large costs associated with the research and development (R \& D) of new drugs. The Pharmaceutical Research and Manufacturers of America estimates that the U.S. industry spent over $\$ 30$ billion on R \& D in 2001. They estimate that, on average, each new marketable drug costs half a billion dollars to develop. ${ }^{183}$ Profits that emanate from pharmacological innovations have to recover high $\mathrm{R} \& \mathrm{D}$ costs.

Patents continue to protect the work of the individual, albeit in a more complex way. Individual inventors may transfer, license or otherwise confer patent rights upon corporate bodies. This transfer is not without consideration, as the individual inventor can expect to be remunerated. It must of course be borne in mind that, unlike the simple tools that existed in previous centuries, modern pharmacological innovations require a complex research infrastructure. When an individual working within the industry invents a patentable idea, they have used R \& D money from their employers. The individual would perhaps not surprisingly waive their rights to claim an interest in the idea they create. These individuals are often engaged in high income jobs. It appears reasonable to sanction the idea that the individual may use this benefit in the way they see fit. There is, however, still some nod in the direction of independence, as Hamilton (1941) notes:

As the corporation became master to his profession, the inventor passed into its service. As he accepts pecuniary allegiance, a vestige of his own status is reserved to him; the device or process which he contrives is initially his property; he applies for a patent and it is issued in his name. But there the cloak of a nominal independence is put off; he is an employee, he works for a salary, his contract obligates him to sign away his rights. ${ }^{184}$

The patent system in the US has changed significantly from the original conception as codified by the founding fathers. This is not to suggest that this process is negative. An institution is not immune to societal changes. In order to survive, the patent system has to change. ${ }^{185}$ When these observations are considered within the debate on patent-

182 See Hanellin, supra note 17, at 186.

183 Carrie Conaway, Too Much of a Good Thing Can be Bad, published at $<\mathrm{http}$ ://www.bos.frb.org/economic/nerr/rr2003/q1/toomuch.htm> 2003 (last visited Sept. 5, 2006).

184 Walton Hamilton, Patents and Free Enterprise (Temporary National Economic Committee, Monograph No. 31) ( $76^{\text {th }}$ Congress 3d Session Senate Committee Print 1941, in Robert P. Merges, Foundations of Intellectual Property, 48 (Foundation Press 2004). It should be noted that under the proposed

185 See id. 
ing TM, it can be appreciated that there can be changes to the system. An example is benefit sharing through contract law (or a prospecting agreement). TK would then be protected like the work of the individual who works for a pharmaceutical company. Money or technology transfer could compensate patent rights that would be signed over to a pharmaceutical company that would develop the drug. A share of the profits could also be stipulated in a contract. Such contracts would be drafted according to national laws, such as the Indian Biological Diversity Act. The patent system can accommodate a range of changes and retain integrity.

\section{CONCLUSION}

There are no simple and uncontroversial answers when dealing with the question of how to legally protect TM. IP rights can be used to protect TK in general, and TM in particular. Patents emerge as a powerful tool to protect TM, particularly when the alternatives are explored. The case is even clearer when public perception is considered. In China patents are a popular method of protecting TM.

This issue has emerged as significant only relatively recently. The 1982 WIPO model provisions did not even have a formulated conception of TK, much less TM. It was only with the CBD in 1992 that the issue came into focus. By this time there was a clear conception of benefit sharing stemming from the idea that the biological and TK resources of a nation was state property. In contrast, the Declaration of the Rights of Indigenous Peoples established that indigenous peoples themselves held these rights. This difficult to implement goal is far from realized. Yet patents can be used to achieve this goal.

International agreements, such as TRIPS, leave the issue of patenting drugs up to national authorities. Until the Patents (Amendments) Act 2005 it was not possible to obtain a product patent on a drug in India. The result is that there have been several high profile cases involving Indian TK in the US. The neem patent controversy is one example. The main issue is that non-US oral traditions are no bar to novelty in a US patent application. The geographical disparity in 35 U.S.C. $\$ 102$ has been credited either with the commercialization of innovations or the destruction of TK by allowing information in the public domain to be patented. In any case US patent law is unlikely to change soon.

India has reacted defensively to American patents based on their TK. The Indian Biological Diversity Act has introduced a number of provisions that will make foreign companies deal with a central authority in order to gain access to Indian biological materials, including TK. India is also working on a database of TK to defeat patent applications for lack of novelty. While the law appears straightforward to implement, the database has raised much opposition. The stakes are high, as bio-piracy is a public concern. Yet some commentators find that the fears of mis-appropriation may be more apparent than real, as in the neem controversy:

Neem's use as a source of pesticide could not and has not been patented. Among the three of the important patents (for derivative uses) for the use of Neem are, one for extracting a 
purer form of azhadirichtin, a second for a more storable stable form, and a third for the use of this compound for cancer treatment. None of these forms of the compound were reported to be similar to the ones found in nature. Also, the use was different from the ones known hitherto. Since these patents do not inhibit use of this compound by anyone extracted through any other method or more or less purity or stability, compensation to the local communities is not due ... ${ }^{186}$

Even if a patent was obtained via misappropriated knowledge, it would not deprive local communities of their right to use their TM. The first hurdle is that it is unlikely that there would be an exact correlation between the patented substance and the locally made product. If there were an exact correlation, the community was a prior user and could prevent the patent holder from prohibiting traditional use. It may be that a community is concerned simply with non-commercial practices. Because a patent is a territorial right, TM that is appropriated and patented in the west may not damage local interests unless there was a serious intention to commercialize the invention in the west. ${ }^{187}$ It is clearly the intention of the Indian government to allow this option. The Biological Diversity Act should prevent blatant bio-piracy by foreign companies.

The main issue is prior informed consent. A group may have no idea of the true value of its TM. If an opportunity to commercialize TM in the west was viable - particularly with a pharmaceutical company as a partner - it may be an option. Western patent laws, such as the US, play a large role internationally. It can be hoped that the newly established National Biological Authority in India can offer guidance on how TM can be patented abroad. Yet according to some, this would be acting contrary to the needs of local communities:

... ethnobotanical knowledge by its very nature is integrative, holistic, and synergistic. It is most meaningful in situ where plants are understood in relation to the ecological and cultural environments in which they have grown, managed and used by local residents. IPR departs from such traditions by valuing the discrete properties of plants that can most easily be taken out of their natural and cultural context ...

Many of the IP group note that the survival of TM is linked with the survival of often fragile minority communities. TM is then just a part of TK, which must be preserved along with all other aspects of language, religion, and culture. When the issue of biological diversity is attached, they would suggest that a simple equation that money equals conservation is a dangerous fallacy. While this view is difficult to counter, it is also hard to appreciate how targeted money - directed at the preservation of biological diversity and TK - would be detrimental. It is difficult to imagine a simple and effective legal solution that would preserve all cultural manifestations of an indigenous community. No one would suggest that patent rights are more than one element in an overall strategy. DO and prospecting agreements fit well with patent protection. In

186 Anil Gupta, Compensating Local Communities for Conserving Biodiversity: How much, Who Will, How and When, published at http://sristi.org/papers/compensating (last visited Sept. 5, 2006).

187 Christopher Heath \& Sabine Weidlich, Intellectual Property: Suitable for Protecting Traditional Medicine, I.P.Q. 77 (2003).

188 See Mugabe, supra note 153, quoting G.R. Nabhan. 
contrast GI and trademark protection are only useful for commercial interests. In the latter two cases the invention would not be protected. At best they can be supplemental to patent protection for TM. Trade secret protection, in placing a veil of secrecy on medications, appears to be least desirable method to protect TM on public policy grounds. All the suggested methods of protection, to some degree, involve the commercialization of TK. Commercialization might be a foreign concept for some groups, but the decision should be for the community concerned to make rather than academics.

There may be cases where certain communities object to the commodification of any of their cultural knowledge or biological material. This does not mean that the entire concept of patent protection of TM is invalid. China has a fully functioning system of patent protection as well as a sui generis regime of protection. TM in China, on the basis of the large number of filed patents, seems well protected and to have a bright future. Yet given that Chinese TM is well integrated with modern science, it may not be a model that can be followed by other TM rich nations.

In sum, the main issue revolves around the needs of the moment. TM right holders should be encouraged to formulate their requirements so that appropriate contracts may be drafted. At the same time legislation, such as the Indian Biological Diversity Act, may serve as a model for other nations. Databases have yet to prove their utility. Given that the public can understand patents, for better or for worse it appears this method is the most practicable way forward. 